\title{
Effect of nontronite smectite clay on the chemical evolution of several organic molecules under simulated Mars surface UV radiation conditions
}

\author{
Olivier Poch ${ }^{1,2 *}$, Maguy Jaber ${ }^{3}$, Fabien Stalport ${ }^{1}$, Sophie Nowak ${ }^{4}$, Thomas \\ Georgelin $^{5}$, Jean-François Lambert ${ }^{5}$, Cyril Szopa ${ }^{6}$ and Patrice Coll ${ }^{1}$
}

${ }^{1}$ LISA, Universités Paris Est Créteil and Paris Diderot, Institut Pierre Simon Laplace, UMR CNRS 7583, 61 Avenue du Général de Gaulle, 94010 Créteil cedex, France

${ }^{2}$ Center for Space and Habitability, University of Bern, Sidlerstrasse 5, CH-3012 Bern, Switzerland

${ }^{3}$ LAMS, UMR CNRS 8220, UPMC Univ. Paris 06, 4 Place Jussieu, 75005 Paris Cedex 5, France

${ }^{4}$ ITODYS, UMR CNRS 7086, Université Paris Diderot, Sorbonne Paris Cité, Bâtiment Lavoisier, 15 Rue Jean-Antoine de Baïf, 75205, Paris, France

${ }^{5}$ LRS, UMR CNRS 7197, UPMC Univ. Paris 06, 3 Rue Galilée, 94200 Ivry, France

${ }^{6}$ LATMOS, UMR CNRS 8970, UPMC Univ. Paris 06, Université Versailles StQuentin, Institut Pierre Simon Laplace, Quartier des Garennes, 11 Boulevard d’Alembert, 78230 Guyancourt, France

*Corresponding author:

Olivier Poch, Center for Space and Habitability, University of Bern, Sidlerstrasse 5, CH-3012 Bern, Switzerland, Phone: +41 3163133 93; Fax: +41 3163144 05; Email: olivier.poch@csh.unibe.ch

Running title: Organics evolution in nontronite on Mars 


\section{Abstract:}

2 Most of the phyllosilicates detected at the surface of Mars today are

3 probably remnants of ancient environments that sustained long term bodies of

4 liquid water at the surface or subsurface and were possibly favorable for the

5 emergence of life. Consequently, phyllosilicates have become the main mineral

6 target in the search for organics on Mars. But are phyllosilicates efficient at

7 preserving organic molecules under current environmental conditions at the

8 surface of Mars?

9 We monitored the qualitative and quantitative evolutions of glycine, urea,

10 and adenine in interaction with the $\mathrm{Fe}^{3+}$-smectite clay nontronite, one of the most

11 abundant phyllosilicates present at the surface of Mars, under simulated martian

12 surface ultraviolet light (190-400 nm), mean temperature (218 $\pm 2 \mathrm{~K}$ ), and

13 pressure (6 \pm 1 mbar) in a laboratory simulation setup. We tested organic-rich

14 samples that were representative of the evaporation of a small, warm pond of

15 liquid water containing a high concentration of organics. For each molecule, we

16 observed how the nontronite influences its quantum efficiency of

17 photodecomposition and the nature of its solid evolution products.

18 The results reveal a pronounced photoprotective effect of nontronite on the

19 evolution of glycine and adenine; their efficiencies of photodecomposition were

20 reduced by a factor of 5 when mixed at a concentration of $2.6 \times 10^{-2}$ mole of

21 molecules per gram of nontronite. Moreover, when the amount of nontronite in 
1 the sample of glycine was increased by a factor of two, the gain of 2 photoprotection was multiplied by a factor of five. This indicates that the

3 photoprotection provided by the nontronite is not a purely mechanical shielding

4 effect, but is also due to stabilizing interactions. No new evolution product was

5 firmly identified, but the results obtained with urea suggest a particular reactivity

6 in the presence of nontronite, leading to an increase of its dissociation rate.

\section{Keywords:}

9 Mars surface; Organic chemistry; Photochemistry; Astrochemistry; Nontronite;

10 Phyllosilicates

\section{1. Introduction}

15 The combined presence of liquid water, organic molecules, and energy 16 sources seems necessary to allow the emergence of life on a planet (Davis and 17 McKay, 1996). A study of the oldest terrestrial rocks indicates that these 18 conditions were met only a few hundred millions years after the formation of our 19 planet (Valley et al., 2002). However, the number and the quality of the oldest

20 records of life are limited, due to the constant renewal of the surface of Earth

21 through present life itself, erosion, and mostly plate tectonics (Condie, 2011). 
1 The planet Mars, which is smaller than Earth, quickly dissipated its

2 internal energy, and its tectonic activity declined after a few hundred million years

3 (Albarede, 2009), which aided in preservation of very ancient geological

4 formations (older than 3.8 Gy) to the present (Solomon et al., 2005). Orbital

5 analyses of these ancient geological formations, which constitute about $50 \%$ of

6 the surface (Tanaka et al., 2013), show that early Mars could have experienced all

7 the conditions required for the emergence of life, especially liquid water. The

8 latter is revealed by the presence of geomorphological (valley networks,

9 sedimentary formations) and geochemical (hydrated minerals) records, in

10 particular phyllosilicates (Bibring et al., 2006; Fassett and Head Iii, 2008; Westall

11 et al., 2013). Consequently, an ambitious exploration program aims to

12 characterize the past habitability of Mars and search for evidence of extinct or

13 extant life on its surface and subsurface (Hoehler and Westall, 2010; Mustard et

14 al., 2013; Vago et al., 2006). The search for organic molecules is the key feature

15 of this exploration program, because in situ detection of indigenous organics

16 could provide clues of life (biomolecules) or habitable conditions (presence of

17 building blocks of life, i.e., molecules related to prebiotic chemistry) on present or

18 ancient Mars (Parnell et al., 2007). The NASA Curiosity rover has been in search

19 of organic molecules in Gale crater since August 2012. The ESA ExoMars 2018

20 rover, along with the "Mars 2020" rover, will pursue this search for organics in 
1 other landing sites of interest in the near future. Thus, the detection of organic

2 molecules is one of the most challenging goals of the exploration of Mars.

3 While space missions to Mars have investigated relatively young martian

4 geological formations, but have not succeeded in detecting organics, recent

5 advances in landing technology will enable future missions to analyze ancient

6 martian formations in which hydrated minerals have been detected from orbit that

7 indicate a watery past. Among them, phyllosilicates are exciting targets because

8 they are known to concentrate and preserve organics on Earth, even in oxidizing

9 environments (Bonaccorsi, 2011). Because of their lamellar structure (see Fig. 2),

10 phyllosilicates offer a high surface of contact for organic molecule adsorption, not

11 only around the mineral grains, but also inside the grains, in the interlayer space.

12 Thus, on Earth, smectite-type phyllosilicates play a fundamental role in the burial

13 and preservation of organic matter in sedimentary basins (Kennedy et al., 2002).

14 Because these minerals could represent our best chance to find evidence for

15 ancient habitability or life preserved on Mars, phyllosilicates narrow the options

16 for landing site selection for missions devoted to the search for organics.

17 The environmental conditions at the surface of Mars, however, have 18 dramatically changed since the early climatic conditions that favored the

19 formation of the phyllosilicates and the embedding of organic molecules in their

20 mineral matrix. At present, and over the course of the past 3 billion years, UV

21 radiation from the Sun with wavelengths down to $190 \mathrm{~nm}$ (Kuhn and Atreya, 
1 1979) and energetic particles (Dartnell et al., 2007; Pavlov et al., 2012) have

2 penetrated to the surface of Mars, which may have brought about the evolution of

3 organic molecules via direct photolysis and/or oxidation processes (Zent and

4 McKay, 1994). It is therefore essential to understand the chemical evolution of

5 organic molecules potentially produced or brought to the surface of Mars in this

6 particular environmental context. Several studies have already focused on the

7 evolution of pure organic molecules under simulated martian surface conditions

8 (Gerakines and Hudson, 2013; Hintze et al., 2010; Johnson and Pratt, 2010; Oro

9 and Holzer, 1979; Poch et al., 2014; Poch et al., 2013; Schuerger et al., 2008;

10 Stalport et al., 2008; 2009; Stalport et al., 2010; Stoker and Bullock, 1997; Ten

11 Kate et al., 2006; Ten Kate et al., 2005), but fewer have assessed the influence of

12 the mineral matrix (Garry et al., 2006; Shkrob and Chemerisov, 2009; Shkrob et

13 al., 2010; Stalport et al., 2010). The radiation source we focused on for this study

14 was the ultraviolet radiation that reaches the surface of Mars. As previously

15 mentioned, photons of wavelengths shorter than $190 \mathrm{~nm}$ are efficiently absorbed

16 by the $95 \%$ of carbon dioxide present in the martian atmosphere (Kuhn and

17 Atreya, 1979; Patel et al., 2002). The absorption cross section of carbon dioxide

$18\left(10^{-23} \mathrm{~cm}^{2}\right.$ at $\left.195 \mathrm{~nm}\right)$ is even higher at lower wavelengths $\left(10^{-18} \mathrm{~cm}^{2}\right.$ at $130-150$

$19 \mathrm{~nm}$, and $10^{-17} \mathrm{~cm}^{2}$ around 98-120 nm) (Huestis et al., 2008; Kuhn and Atreya,

20 1979). Also, some studies have shown that X-radiation does not penetrate

21 efficiently through the martian atmosphere, even though it is thin (Smith et al., 
1 2004; Smith et al., 2007; Jain et al., 2012). So virtually no photon of wavelength

2 shorter than $190 \mathrm{~nm}$ reaches the surface of Mars, except gamma-rays and other

3 high energy heavy particles from cosmic rays (Dartnell et al., 2007). Some studies

4 have investigated the influence of energetic particles on the evolution of organics

5 at the surface of Mars (Gerakines et al., 2012; Kminek and Bada, 2006). The

6 results show that these radiations can cause the degradation of simple organic

7 molecules (glycine) on a timescale of hundreds of millions of years, while UV

8 radiation acts on a much shorter timescale (several days to months) (see for

9 example Poch et al., 2014). On the other hand, higher energy radiation can

10 penetrate deeper into the soil (up to around two meters) than UV radiation (up to

11 few microns or millimeters).

12 Because phyllosilicates are presently the main mineral target for the search

13 for organics on Mars, it seems essential to test the processes organic molecules

14 might have undergone in these preferential mineral matrixes. Consequently, the

15 present study is the first to consider the evolution of organic molecules in

16 interaction with phyllosilicates under simulated Mars surface conditions.

17 Simulations were carried out with the MOMIE (Mars Organic Molecules

18 Irradiation and Evolution) experimental setup (Poch et al., 2013), which

19 reproduces the UV radiation environment at the surface of Mars (from 190 to 450

$20 \mathrm{~nm}$ ) along with the mean martian temperature and pressure (respectively $218 \pm 2 \mathrm{~K}$

21 and $6 \pm 1$ mbar). We studied the evolution of glycine, adenine, and urea, three 
1 water-soluble molecules representative of endogenous and exogenous sources at

2 Mars, in the presence of $\mathrm{Fe}^{3+}$-nontronite. Nontronite is an iron rich smectite clay

3 (Palchik et al., 2013) whose spectral signature is widespread at the surface of

4 Mars (Ehlmann et al., 2013; Ehlmann et al., 2011; Mustard et al., 2008),

5 especially on the flanks of the central mount of Gale crater in the form of a tens of

6 meters thick deposit (Milliken et al., 2010; Poulet et al., 2014; Thomson et al.,

7 2011). These sedimentary formations constitute the main science objective of the

8 Curiosity rover in its search for organics.

9 In this context, the present article aims to provide some answers to the 10 following questions: What is the effect of nontronite clay on the evolution of

11 organic molecules under Mars current environmental conditions? Are clay

12 minerals effective at preserving organic molecules even under Mars surface UV

13 radiation during long geological scales? Or did they trigger processes resulting in

14 the destruction of the molecular structures (namely, photocatalysis or

15 stoichiometric oxidation reactions with $\mathrm{Fe}^{3+}$ or $\mathrm{HO}$. from adsorbed $\mathrm{H}_{2} \mathrm{O}$ for

16 example)?

17

18

19 2. Materials and Methods

20 
1 We exposed glycine, adenine, and urea to simulated martian surface 2 conditions in presence of nontronite clay mineral. The simulations were 3 performed with the MOMIE experimental setup. This setup is briefly described in

4 the paragraph below. A more detailed description can be found in the work of $5 \quad$ Poch et al. (2013).

$7 \quad$ 2.1. Mars surface conditions simulated inside the MOMIE setup

9 The MOMIE setup allows investigators to simulate the in situ Mars-like 10 UV irradiation and proceed to FTIR (Fourier Transform Infrared Spectroscopy)

11 monitoring of the sample, at a temperature (218 $\pm 2 \mathrm{~K})$ and pressure (6 $\pm 1 \mathrm{mbar})$

12 representative of the mean conditions at the martian surface.

13 The studied sample consisted of thin uniform layers (micrometric scale)

14 made of a mixture of nontronite and organics, deposited on a $\sim 2 \mathrm{~cm}$ diameter 15 magnesium fluoride $\left(\mathrm{MgF}_{2}\right)$ optical window. The samples were prepared via 16 evaporation/sedimentation of a nontronite-organic suspension. The sample 17 preparation method is detailed below (section 2.2). We also prepared pure organic 18 samples without nontronite, whose preparation and evolution is detailed in the 19 works of Poch et al. (2013) and Poch et al. (2014). In the present study, these 20 samples were procedural references used to deduce the influence of nontronite on 21 the molecular evolution. The $\mathrm{MgF}_{2}$ window with the sample was then placed 
1 inside the reactor of the MOMIE setup (see Fig. 1 and 2 of Poch et al. (2013)).

2 The sample was irradiated with a Xenon arc lamp, and analyzed by FTIR 3 spectroscopy.

4 The whole MOMIE setup was placed in a glove compartment that was

5 purged and over-pressurized with $\mathrm{N}_{2}(\geq 99.995$ vol. \% from Linde) to prevent the

6 formation of ozone and water ice. For the duration of an experiment, the reactor

7 was thermostated at $218 \pm 2 \mathrm{~K}$ with a cryothermostated fluid circulation. It was

8 connected to a pumping system that maintained a pressure of $6 \pm 1$ mbar of $\mathrm{N}_{2}$.

9 Since a former study by ten Kate et al. (2006) did not show any impact of a

10 representative Mars atmosphere of carbon dioxide on the evolution of glycine

11 samples exposed to UV radiation, comparatively to a pure $\mathrm{N}_{2}$ atmosphere, we

12 chose to perform our simulation in a 6 mbar atmosphere of $\mathrm{N}_{2}$.

16 The lamp delivers UV light with a spectrum similar to that which reaches 17 the martian surface as modeled by Patel et al. (2002) (see Fig. 1). The lamp flux

18 is, however, much higher than that on Mars (see Fig. 1), which allows for 19 simulation of long periods of irradiation on Mars in reasonable lapse time in the

20 laboratory. The absolute irradiance spectrum shown in Fig. 1 was measured at the

21 sample location inside our simulation setup in the 190-400 nm wavelength range 
1 with a radiocalibrated UV spectrometer (Black Comet C50, from StellarNet Inc.,

2 US). An integrating sphere was substituted for the sample to proceed to the

3 measurement of the UV flux under a $\mathrm{N}_{2}$ atmosphere. Data in the 200-220 nm

4 range (shown with individual crosses) suffered from uncertainties due to stray

5 light and temperature variations in the spectrometer. Nevertheless, the bulb and

6 lens used were made of fused silica that cuts off the light between 180 and 190

7 nm, which prevents any photon of higher energy to interact with our sample. The

8 experimental uncertainties on the amount of photons reaching the samples are

9 taken into account as described in details in section 2.3 of Poch et al. (2014). The

10 Xenon lamp also generates a large amount of infrared photons. We verified that

11 the infrared photons received by our sample had a negligible impact on its

12 chemical evolution (see Poch et al. (2013) for more details).

13 Furthermore, we performed reference experiments to test the

14 stability/sublimation of the studied organic thin films under 6 mbar and $218 \mathrm{~K}$,

15 but without UV irradiation, in our simulation chamber. The results of these

16 reference experiments, shown in Appendix C in the work of Poch et al. (2014),

17 demonstrate that no sublimation of the organic deposits occurred under these

18 conditions. Consequently, the chemical evolution we monitored was only due to

19 the UV photons interacting with our samples.

20

21 2.2. Samples description and preparation 
2 Glycine was purchased from VWR BDH Prolabo (98\%, ref. n²4403.298),

3 urea from Alfa Aesar (99.3+\%, ref. n036429), adenine from Sigma-Aldrich

4 (adenine $\geq 99 \%$, ref. $\mathrm{n}^{\circ} \mathrm{A} 8626-25 \mathrm{G}$ ), and each of these three molecules were

5 mixed with nontronite smectite clay. To use a clay mineral free of any organic

6 contamination contained in terrestrial natural samples, nontronite was synthesized

7 from organic-free bulk chemicals (including silica, iron, and aluminum sources)

8 via hydrothermal synthesis according to Andrieux and Petit (2010). Iron chloride

9 (97\%) and sodium metasilicate ( $\geq 99 \%)$ were obtained from Sigma-Aldrich, and

10 aluminum chloride ( $\geq 99 \%$ ) was obtained from Fluka. Moreover, the nontronite

11 was cation-exchanged with $\mathrm{Fe}^{3+}$ in order to increase the probability for organic

12 molecules to be oxidized during the simulation. Indeed, phyllosilicates present at

13 the surface of Mars could contain oxidants as $\mathrm{Fe}^{3+}$ or perchlorates, so it is

14 important to assess whether such "oxidant-enriched clays" can still protect

15 embedded organic molecules under Mars surface conditions. This cation-

16 exchange results in the presence of Fe ions in two very different environments, as

17 substitutional ions in the clay layers, and as compensating ions in the interlayer

18 space; the latter being much more accessible. The cation exchange was conducted

19 by suspending the nontronite $\left(20 \mathrm{~g} \mathrm{~L}^{-1}\right)$ in a 0.5 mol L $\mathrm{L}^{-1}$ organic-free solution of

20 iron (III) chloride. Three contacts of two hours each, followed by filtration, were

21 performed. Nontronite was then washed three times with $100 \mathrm{~mL}$ of distilled 
1 water, separated by centrifugation, and dried at $60^{\circ} \mathrm{C}$. The synthesized nontronite

2 was finally characterized by X-ray diffraction (see Supplementary Figure 1), X-

3 ray fluorescence, transmission electron microscopy (see Fig. 2), and IR

4 transmission spectroscopy (Supplementary Figure 2) as detailed in section 3.1.

5 Samples were prepared so as to maximize the interaction between the

6 organic molecules and the nontronite, with the aim of adsorbing the molecules

7 around but also inside the nontronite grains, in the interlayer space. A $0.3 \mathrm{~g} \mathrm{~L}^{-1}$

8 nontronite suspension was prepared in an aqueous high purity water $8.10^{-3} \mathrm{~mol} \mathrm{~L}^{-1}$

9 solution of the targeted organic molecule (glycine, urea, or adenine), and stirred

10 for more than 2 hours. This procedure enables the clay particles to expand their

11 interlayer space, leaving water and organic molecules enough time to diffuse

12 inside the mineral. Finally, the deposition on the $\mathrm{MgF}_{2}$ window was done by

13 evaporation/sedimentation of $1 \mathrm{~mL}$ of the aqueous suspension by heating the

$14 \mathrm{MgF}_{2}$ window at $50^{\circ} \mathrm{C}$ for 35 minutes. The resulting sample is a homogeneous

15 solid layer of nontronite and organic molecules, ready to be placed inside the

16 MOMIE simulation setup (see Fig. 3a). The samples of glycine, urea, and adenine

17 contained the same number of organic molecules and had a concentration of $2.6 \times$

$1810^{-2}$ mole of organic molecules per gram of nontronite (Table 1 ).

19 The concentrations of nontronite and organics were chosen to suit the

20 constraints of the MOMIE setup (the samples have to be sufficiently optically

21 transparent for UV irradiation and IR spectroscopy analyses). This resulted in 
1 high organic molecule to mineral mass ratios, from (1:1) to (3:1) depending on the

2 molecule (see Table 1). These amounts of organic molecules definitely exceed

3 those that could be interacting with the mineral phase, even assuming that a dense

4 monolayer is formed on the whole clay surface. Therefore, some organic

5 molecules in our samples were not interacting with the clay phase. This fact has

6 been taken into account for the analyses of the results by comparing the

7 qualitative and quantitative observations from experiments performed in the

8 presence of nontronite to those performed on samples of pure organic molecules,

9 as explained in section 4 .

11 2.3. Analyses of the samples before, during, and after simulations

13 Before being placed inside the MOMIE simulation chamber, the deposits

14 of nontronite and organics on the $\mathrm{MgF}_{2}$ windows were imaged with a visible

15 microscope (Fig. 3a) and an interference microscope (WYKO NT1100 Optical

16 Profiling System by Veeco). The interference microscope enabled us to obtain a

17 local topographic map of the sample (Fig. 3b).

18 X-ray diffraction (XRD), X-ray fluorescence (XRF), and transmission

19 electron microscopy (TEM) measurements were performed on the dry solid

20 fraction obtained after the complete evaporation of the suspensions in order to

21 verify the intercalation of the organic molecules inside the interlayer space of the 
1 clay (see section 2.2). The technical details of these measurements can be found in

2 the Supplementary Material document.

3 Inside the MOMIE simulation chamber, IR transmission spectra of the 4 samples (from 7000 to $1000 \mathrm{~cm}^{-1}$ ) were acquired in situ throughout the

5 simulations. The IR data allowed us to quantify the photolysis decay of the

6 irradiated molecules by monitoring the decay of absorption bands specific of the

7 studied compound. Alternatively, the emergence of new IR absorption bands

8 indicates the formation of new solid photoproducts during the simulation. Spectra

9 (noted $I$ ) were acquired by using a FTIR spectrometer (Spectrum 100 from Perkin

10 Elmer) with 50 scans at a resolution of $2 \mathrm{~cm}^{-1} . I / I_{\text {ref }}$ ratios were calculated with

11 reference spectra $\left(I_{r e f}\right)$ obtained under the same experimental conditions with a

12 clean $\mathrm{MgF}_{2}$ sample window.

13 UV transmission spectra were performed ex situ before and after 14 simulation with a "Cary 60" UV-Vis spectrometer (Agilent Technologies). They 15 provide information on the evolution of the UV absorption of the samples in the $16 \quad$ 190-300 nm range.

18 2.4. Determination of kinetic parameters for organics mixed with $\mathrm{Fe}^{3+}$-nontronite 19 under Mars surface UV 
1 Quantitatively, our main objective in this study was to determine whether

2 the interaction of the organic molecules with the $\mathrm{Fe}^{3+}$-nontronite clay would

3 accelerate the degradation of the molecules or if the clay would attenuate the

4 effect of Mars surface UV irradiation. So we had to compare kinetic parameters

5 obtained after simulations on each targeted organic molecule with and without

6 nontronite. Kinetic parameters of pure glycine, urea, and adenine were determined

7 by Poch et al. (2014), who used the MOMIE setup. These samples consisted of

8 nanometers thin (10-200 nm) organic deposits obtained by sublimation (heating of

9 the organic powder at reduced pressure) and recondensation on a $\mathrm{MgF}_{2}$ window.

10 By comparison, the samples of nontronite and organics used in the present study

11 were obtained by evaporation/sedimentation (see section 2.2) and contained

12 approximately 10 times more molecules than the samples studied by Poch et al.

13 (2014). The results presented by Poch et al. (2014) show that the photolysis rates

$14 J$ and half-life times $t_{1 / 2}$ determined from the simulations strongly depend on the

15 initial number of molecules in the sample. Therefore, we did not determine these

16 parameters to compare the evolution of molecules with and without nontronite.

17 Alternatively, we determined the experimental quantum yields of

18 photodissociation in the presence of nontronite, because Poch et al. (2014)

19 showed that for a given molecule these experimental values are independent of

20 the initial number of molecules in the samples. For example, we found similar

21 values of the adenine quantum efficiency of photodecomposition determined after 
1 an experiment performed on a sample of adenine about $70 \mathrm{~nm}$ thick $\left(1.1 \pm 1.0 \times 10^{-4}\right.$

2 molecule photon $\left.{ }^{-1}\right)$ and $1300 \mathrm{~nm}$ thick $\left(1.0 \pm 0.9 \times 10^{-4}\right.$ molecule photon $\left.^{-1}\right)$, the latter

3 sample containing the same amount of adenine as the one we prepared with

4 nontronite. Therefore, any difference seen in the value of the adenine quantum

5 efficiency of photodecomposition in the presence of nontonite indicates the

6 influence of the mineral on the chemical evolution of adenine. To conclude,

7 quantum yields of photodissociation are molecular data and allow us to assess the

8 influence of the nontronite on the molecular evolution; a lower yield in the

9 presence of nontronite will indicate a photoprotection of the molecule, while a

10 higher yield will indicate a catalytic effect of the nontronite on the

11 photodecomposition of the molecule.

12 After each simulation, the experimental quantum efficiency of

13 photodecomposition from 200 to $250 \mathrm{~nm}, \Phi_{\text {exp }}$ was determined. $\Phi_{\text {exp }}$ is the ratio

14 of the number of molecules photodissociated to the number of photons from 200

15 to $250 \mathrm{~nm}$ reaching the molecular deposit during its irradiation. The details of the

16 calculation of $\Phi_{\text {exp }}$ in both cases (pure organics or organics mixed with

17 nontronite) are described in the Supplementary material document.

\section{3. Results}


3 The X-ray diffractogram of the synthesized mineral (Supplementary

4 Figure 1a) shows low intensity diffraction peaks, indicating a low crystallinity of

5 the mineral. Comparison with diffractograms of natural nontronite samples (color

6 bars Supplementary Figure 1a) indicates that most of the diffraction peaks of the

7 synthesized mineral match those of natural nontronites; some of them, however,

8 could not be assigned to nontronite. The (001) peak at around $2 \theta=7^{\circ}$ appears

9 poorly resolved, suggesting a heterogeneous stacking of the clay layers. However,

10 transmission electron microscopy images of the synthesized mineral locally show

11 the layering characteristic of clay minerals (see Fig. 2), with an interlayer width

12 comprised between 1.3 and $1.7 \mathrm{~nm}$. These values are consistent with the fact that

13 the (001) peak is centered at $2 \theta=7^{\circ}$, corresponding to a mean interlayer space of

$14 \quad 1.5 \mathrm{~nm}$. The result of the elementary analysis performed by X-ray fluorescence on

15 the synthesized nontronite allowed us to calculate the following chemical

16 formulae $\mathrm{H}^{+}{ }_{0.3} \mathrm{Fe}_{0.3}\left(\mathrm{Fe}^{3+}{ }_{2.0}\right)\left(\mathrm{Si}_{2.8} \mathrm{Al}_{1.2}\right) \mathrm{O}_{10}(\mathrm{OH})_{2}$. To conclude, the synthesized

17 nontronite used in this study was a low crystalline $\mathrm{Fe}^{3+}$-rich nontronite. 
1 An example of a sample obtained from evaporation/sedimentation of a 2 suspension of nontronite and an organic molecule on a $\mathrm{MgF}_{2}$ window is presented

3 in Fig. 3a. The topographic map obtained by interference microscopy (Fig. 3b)

4 shows that the thin layer deposited on the $\mathrm{MgF}_{2}$ window contains grains

5 (aggregates of clay and organics) of all sizes up to $25 \mu \mathrm{m}$. The organic molecule is

6 present around, and probably inside, the grains, but also between the grains, in the

7 form of a crystalline layer less than $1 \mu \mathrm{m}$ thick.

8 Although the sample preparation protocol should permit the adsorption of

9 the molecules outside (on the layer edges), but also inside the interlayer space of

10 the nontronite clay, the diffractograms (Supplementary Figure 1b) and TEM

11 images (Fig. 2) of the samples do not show an obvious increase of the interlayer

12 space of the nontronite in the presence of organic molecules. Thus, either the

13 organic molecules were not intercalated, or because of their small size (in the case

14 of glycine and urea) or flat structure (in the case of adenine) they may have been

15 positioned parallel to the clay layers so that they did not produce an obvious

16 difference of interlayer width. To provide more indications on the ways the

17 studied molecules might interact with the nontronite in our samples, we reviewed

18 the published literature in the Supplementary Material.

19 The nontronite present in the deposit is responsible for a high absorption

20 of UV radiation. The average transmittance of the deposits in the $190-300 \mathrm{~nm}$ 
1 wavelength range is $38 \pm 5 \%$. The UV transmittance of the samples was not

2 significantly changed after UV irradiation.

3 The IR transmission spectra of the samples of nontronite mixed with

4 organic molecules (glycine, urea, or adenine) are shown as black lines in Fig. 4a,

5 Fig. 6a, and Fig. 8a. These spectra show the main infrared absorption bands of

6 glycine (Fig. 4a), urea (Fig. 6a), or adenine (Fig. 8a), superimposed on the

7 spectral features due to the nontronite: two absorptions at 3694 and $3617 \mathrm{~cm}^{-1}$

8 corresponding to stretching vibrations of $\mathrm{O}-\mathrm{H}$ bonds in the clay structure, and a

9 "blue slope" on the whole spectrum, from $4000 \mathrm{~cm}^{-1}$ to $1000 \mathrm{~cm}^{-1}$, due to the

10 scattering of the infrared beam through the micrometer-thick deposit (see

11 Supplementary Figure 2). The labels (a, b, c, etc.) shown on each of the

12 absorption bands refer to the assignments of these bands to molecular bond

13 vibrations detailed in Supplementary Table 1 for glycine, Supplementary Table 2

14 for urea, and Supplementary Table 4 for adenine. Some absorption bands in the

$153500-2500 \mathrm{~cm}^{-1}$ wavelength range appear broader or slightly shifted in the

16 presence of nontronite, but no significant shift of the absorption bands

17 wavelengths has been spotted for the samples of molecules mixed with nontronite,

18 compared to pure organic samples. However, the IR spectrum of the non-

19 irradiated sample of urea mixed with nontronite shows a very weak absorption

20 band at $1350 \mathrm{~cm}^{-1}$, which is absent in the spectrum of pure urea (see

21 Supplementary Table 2 and Fig. 6a and b). According to Mortland (1966), this 
1 absorption band could be due to an interaction between the free electrons of the

$2-\mathrm{NH}_{2}$ groups of urea and the metal cation from the clay mineral $\left(\mathrm{Fe}^{3+}\right.$ in our case), 3 modifying the $\mathrm{CN}$ stretching and the $\mathrm{HNH}$ deformation of the amide group.

4

5

-----Figure 3 should be here-----

6

7

8 3.3. Evolution of the samples during and after UV irradiation at simulated Mars

9 surface conditions

10

11 3.3.1. Pure nontronite

12

13 We performed a reference experiment that involved UV irradiation of a 14 sample of pure nontronite to discern the evolution of its infrared spectrum. This

15 experiment, detailed in the Supplementary Material document, showed that only

16 the infrared bands in the 2700 to $1400 \mathrm{~cm}^{-1}$ range can be used for the processing

17 of the IR spectra and the determination of kinetic parameters of the molecules.

18

19 3.3.2. Glycine

20

21 3.3.2.1. Qualitative evolution 
2 The evolution of the IR spectrum of a sample of nontronite with glycine 3 under UV irradiation in simulated martian conditions is presented in Fig. 4a. The 4 decreasing intensity of the infrared bands of glycine (labels) is due to the 5 photodecomposition of the molecule. These spectra also show the emergence of 6 new absorption features (red arrows in Fig. 4a): one at $3240 \mathrm{~cm}^{-1}$ and extending

7 up to $3500 \mathrm{~cm}^{-1}$, and the other at $1720-1680 \mathrm{~cm}^{-1}$. These new absorptions exactly 8 match those obtained during the irradiation of pure glycine (see Fig. 4b and Poch 9 et al. (2013)). According the analysis of Poch et al. (2013), the band at 1720-1680 $10 \mathrm{~cm}^{-1}$ would be due to the stretching vibration of amide products due to the 11 formation of peptide bonds during irradiation, and the band at $3240 \mathrm{~cm}^{-1}$ is due to 12 the water produced during this reaction. -----Figure 4 should be here-----

\subsubsection{Quantitative evolution} The relative abundance of glycine was determined after each irradiation 18 period by averaging the absorption maxima of the bands at $2603 \mathrm{~cm}^{-1}$ (g label, $\left.19 \delta_{\mathrm{as}} \mathrm{NH}_{3}^{+}+v \mathrm{CN}\right), 1524 \mathrm{~cm}^{-1}\left(\mathrm{~m}\right.$ label, $\delta_{\mathrm{s}} \mathrm{NH}_{3}^{+}$), and $1418 \mathrm{~cm}^{-1}$ (n label, $v_{\mathrm{s}} \mathrm{COO}^{-}$)

20 (see Fig. 4 and Supplementary Table 1). The average relative abundance derived 21 from this treatment is shown as a function of irradiation time in Fig. 5. The 
1 decrease of the relative quantity of glycine slows down dramatically when

2 increasing the irradiation time. This evolution matches (correlation coefficient $\mathrm{R}^{2}$

$3>0.995)$ a kinetic model where the quantity of glycine reaches a plateau after a

4 certain irradiation time:

$$
\left.\frac{N_{t}}{N_{0}}=\left(1-\frac{N_{\infty}}{N_{0}}\right) \times e^{-J t}+\frac{N_{\infty}}{N_{0}} \text { (Equation } 1\right)
$$

6 with $N_{t}$ the quantity of molecules after t minutes of irradiation, $N_{0}$ the quantity of

7 molecules before any irradiation, and $N_{\infty}$ the constant quantity of molecules after

8 a very long irradiation time $(\mathrm{t} \rightarrow \infty)$.

9 This kinetic could be explained as follows: (1) the photoprotection of

10 glycine molecules by the nontronite present on the sample: we first observed the

11 photodecomposition of the unprotected molecules, and then the quantity of

12 glycine tends toward $N_{\infty}$ which is the quantity of glycine photo-protected by the

13 nontronite; and/or (2) the establishment of an equilibrium between the

14 photodissociation of glycine and its reverse reaction, both being activated by UV

15 radiation: "Glycine $\leftrightarrow$ Products." This latter process could be explained by the

16 presence of the nontronite, or it could be due to the large amount of glycine in the

17 deposit. Indeed, the same kinetic was observed for a thick sample of pure adenine,

18 without the presence of nontronite (see section 3.3.4.2 and Fig. 4).

19 To validate this point, a simulation experiment was carried out on another 20 sample of glycine containing the same quantity of molecules but with a doubled 
1 concentration of nontronite $\left(0.6 \mathrm{~g} \mathrm{~L}^{-1}\right.$, "glycine $+2 \mathrm{Xnontronite}+\mathrm{UV}^{\mathrm{N}}$ in Fig. 5).

2 Fig. 5 shows that a doubling of the amount of nontronite in the sample leads to a

3 slower photodecomposition of glycine. The decrease of the relative quantity of

4 glycine is fitted by the kinetic model described above (Equation 1), with a plateau

$5\left(N_{\infty}\right)$ at a higher value. We interpret this observation in terms of a better

6 photoprotection provided by the higher amount of clay mineral.

7 The quantum efficiency of photodecomposition of glycine $\left(6.3 \pm 5.2 \times 10^{-3}\right.$

8 molecule photon ${ }^{-1}$ ) is reduced by a factor of 5 in the presence of nontronite

$9\left(1.2 \pm 1.1 \times 10^{-3}\right.$ molecule photon $\left.^{-1}\right)$ and is even reduced again by another factor of

105 when the sample contains twice the concentration of nontronite $\left(2.4 \pm 2.1 \times 10^{-4}\right.$

11 molecule photon ${ }^{-1}$ ) (see Table 1 ). These observations clearly indicate a strong

12 photoprotection provided by the nontronite.

15 3.3.3. Urea

\subsubsection{Qualitative evolution}

19 The evolution of a sample of nontronite with urea under UV irradiation in

20 simulated martian conditions is presented in Fig. 6a. These IR spectra show the

21 decreasing intensity of the IR bands of urea (labels, cf. Supplementary Table 2), 
1 due to its photodecomposition, and the emergence of three new absorption

2 features in the $2100-2300 \mathrm{~cm}^{-1}$ range. The bands centered at $2170 \mathrm{~cm}^{-1}$ and 2200

$3 \mathrm{~cm}^{-1}$ are also observed in the simulations performed in the absence of nontronite

4 (see Fig. 6b), and they correspond to the stretching vibrations of the cyanate ion

5 OCN $^{-}$(see Supplementary Table 3). The third band, around $2250-2220 \mathrm{~cm}^{-1}$, is

6 absent in simulations performed on pure urea (see Fig. 6b). It may be due to a new

7 vibration mode related to the interaction of cyanate ion or $\mathrm{O}=\mathrm{C}=\mathrm{N}-\mathrm{H}$ isocyanic

8 acid (Lowenthal et al. 2002) with compensating $\mathrm{Fe}^{3+}$ ions or with the nontronite

9 surface. Additionally, the spectra observed in the presence of nontronite (Fig. 6b)

10 do not show any evidence of the ammonium ion $\mathrm{NH}_{4}{ }^{+}$, which is characterized by

11 IR bands located at $1440 \mathrm{~cm}^{-1}$ and between 3169 and $2872 \mathrm{~cm}^{-1}$ in spectra of pure

12 UV irradiated urea (see Supplementary Table 3 and Supplementary Fig. 2 of Poch

13 et al. (2014)). Moreover, in the presence of nontronite, the band corresponding to

14 the stretching vibration of CO to $1596 \mathrm{~cm}^{-1}$ (label f) has the fastest decrease rate,

15 while for pure urea the $\mathrm{CN}$ band at $1470 \mathrm{~cm}^{-1}$ (label g) has the fastest decay. All

16 these data put together indicate that the chemical evolution of urea under UV

17 irradiation conditions is different in the presence of nontronite from that of bulk

18 urea. This change in reactivity is certainly related to the fact that urea shows an

19 interaction with the mineral, as evidenced by the $1350 \mathrm{~cm}^{-1}$ absorption band

20 discussed above (see the last paragraph of section 3.2). 


\section{$2 \quad$ 3.3.3.2. Quantitative evolution}

4 The relative abundance of urea (Fig. 7) was determined after each

5 irradiation period by averaging the absorption maxima of the bands at $1681 \mathrm{~cm}^{-1}$

6 (label d, $\delta_{\mathrm{s}} \mathrm{NH}_{2}$ ), $1627 \mathrm{~cm}^{-1}$ (label e, $\delta_{\text {as }} \mathrm{NH}_{2}$ ), $1596 \mathrm{~cm}^{-1}$ (label f, vCO), and 1471

$7 \mathrm{~cm}^{-1}$ (label g, $v_{\mathrm{as}} \mathrm{CN}$ ) (see Fig. 6a and Supplementary Table 2). The three

8 experimental points obtained after irradiation match a first order decay. Though

9 the total amount of photons received during the simulation is small, the observed

10 trend of the quantity of urea does not seem to tend towards an equilibrium value,

11 contrary to what is observed for glycine (Fig. 5).

12 The quantum efficiency of photodecomposition calculated for urea in the 13 presence of nontronite $\left(2.9 \pm 2.3 \times 10^{-3}\right.$ molecule photon $^{-1}$, Table 1$)$ is potentially 14 twice as high as in the absence of nontronite $\left(1.3 \pm 6.0 \times 10^{-3}\right.$ molecule photon $\left.^{-1}\right)$, 15 but the large error bars on these values prevent any definitive conclusion. This 16 increase of photodecomposition efficiency could be due to the occurrence of 17 additional pathways leading to the degradation of urea because of the presence of 18 nontronite, such as photocatalysis or stoichiometric oxidation reactions with $\mathrm{Fe}^{3+}$, $19 \mathrm{H}_{2} \mathrm{O}$, or $\mathrm{HO}$. 


\section{$3 \quad$ 3.3.4.1. Qualitative evolution}

4

5 The spectra that show the evolution of a sample of adenine in the presence

6 of nontronite under UV irradiation in simulated martian conditions are presented

7 in Fig. 8a. The intensity of the IR bands of adenine (labels, Supplementary Table

8 4) decreases due to the photodecomposition of the molecule, and new absorption

9 features emerge: a broad absorption from 3600 to $3000 \mathrm{~cm}^{-1}$, a narrower

10 absorption band between 2170 and $2160 \mathrm{~cm}^{-1}$, and a broader absorption from

111780 to $1500 \mathrm{~cm}^{-1}$. The same new absorptions are observed after the UV

12 irradiation of pure adenine (see Fig. 8b). Poch et al. (2014) assigned these

13 absorptions to a (or several) product(s) possibly consisting of primary amine

14 functional groups $\left(-\mathrm{NH}_{2}\right)$, isocyanides $(\mathrm{R}-\mathrm{N} \equiv \mathrm{C})$, and/or nitriles $(\mathrm{R}-\mathrm{C} \equiv \mathrm{N})$

15 involved in an extended conjugated system (as $-\mathrm{C}=\mathrm{C}-\mathrm{C}=\mathrm{N}-$ ). As in the case of

16 glycine, no new infrared band is observed for adenine in the presence of

17 nontronite that has not been observed as well for the evolution of the pure organic

18 samples under UV irradiation.

19

-----Figure 8 should be here-----

20

21 3.3.4.2. Quantitative evolution 
2 The relative abundance of adenine in the presence of nontronite during the

3 simulation is shown in Fig. $9(\bullet)$. On the same figure is also shown the relative

4 abundance of a sample containing the same amount of adenine, but without

5 nontronite $(\circ)$. These data were obtained by integrating the adenine infrared band

6 at $1603 \mathrm{~cm}^{-1}$ (label h). It can be seen that nontronite provides a photoprotective

7 effect that significantly slows down the photodecomposition rate of adenine. This

8 is also confirmed by the determination of the photodissociation yields presented in

9 Table 1 ; the value obtained in the presence of nontronite $\left(2.0 \pm 1.4 \times 10^{-5}\right.$ molecule

10 photon $^{-1}$ ) is reduced by a factor of 5 compared to the value obtained for pure

11 adenine $\left(1.0 \pm 0.9 \times 10^{-4}\right.$ molecule photon $\left.^{-1}\right)$.

12 We note that the relative quantity of adenine contained in the pure organic

13 sample tends toward an asymptotic constant value for a very long irradiation time

14 (following Equation 1) (see Fig. 9). This trend can be explained by the formation

15 of the photoproduct(s) having a shielding effect on the adenine molecules located

16 deeper in the deposit, as was already observed with thinner deposits by Poch et al.

17 (2014). This leveling off of photodegradation in the long term for thick deposits is

18 particularly interesting regarding the photostability of potential solid organic

19 layers on Mars (more details can be found in the work of Poch et al. (2014)).

20 When adenine is in the presence of nontronite, the kinetic is more

21 ambiguous; the aforementioned model (Equation 1) is not well verified 
1 (correlation coefficient $\mathrm{R}^{2}=0.83$ ), nor is the first order decay model (see Fig. 9).

2 This might be indicative of the occurrence of a peculiar process that affects

3 adenine in the presence of nontronite, but because of the high uncertainty on these

4 data we cannot definitively conclude on this point.

5

-----Figure 9 should be here-----

\section{4. Discussion}

9 We exposed samples of glycine, urea, and adenine, all containing the same 10 number of molecules and the same mass of nontronite, to simulated Mars surface

11 conditions: UV radiation (190-400 nm), mean temperature (218 $\pm 2 \mathrm{~K}$ ), and $\mathrm{N}_{2}$

12 atmospheric pressure (6 \pm 1 mbar). These organic molecules were co-deposited

13 with nontronite from aqueous solution. To suit the constraints of our experimental

14 device, the samples had a high mass ratio of organic molecules compared to

15 nontronite (from 1.0 to 3.6). This high mass ratio is certainly not representative of

16 most Mars environments, and in such a case it is difficult to discuss the

17 photoprotection by the mineral. Because of this high mass ratio, a fraction of the

18 organic molecules were probably not in direct chemical interaction with the clay

19 mineral, and various processes could occur in our samples:

20 - (1) photolysis of the molecule directly exposed to the UV radiation,

21 - (2) photoprotection from UV photons provided by the nontronite, 
- (3) conversely, transformation of the molecule as a result of its interaction with the nontronite; the latter could act either as a photocatalyst or as a stoechiometric reagent (e.g., oxidation by $\mathrm{Fe}^{3+}$, reactions with $\mathrm{H}_{2} \mathrm{O}$ etc.),

4 To discern the influence of the nontronite on the chemical evolution of the studied

5 molecules (processes (2) or (3)), we had to eliminate the consequences of direct

6 photolysis (process (1)). Poch et al. (2014) documented the consequences of direct

7 photolysis on glycine, urea, and adenine by determination of the nature of the

8 photoproducts and the molecular quantum efficiencies of photodecomposition.

9 Comparing these results with the those obtained in the presence of nontronite

10 enabled us to deduce what the influence of the nontronite was on the chemical

11 evolution of the studied molecules (processes (2) or (3)). It should be noted that

12 even when we had to compare very different types of samples (pure organic

13 samples versus organics mixed with nontronite), we found a way to make a

14 quantitative comparison by determining in each case the quantum efficiencies of

15 photodecomposition of the molecules (presented in Table 1), as we explain in 16 section 2.4 .

19 4.1. Photoprotection or photodecomposition of the organic molecules provided by

20 the $\mathrm{Fe}^{3+}$-nontronite 
1 The molecular photodissociation yields calculated for glycine, urea, and

2 adenine in the presence of nontronite are compared with those obtained in the

3 absence of nontronite in Fig. 10 and Table 1. When mixed at a concentration of

$42.6 \times 10^{-2}$ mole of molecules per gram of nontronite, glycine and adenine have

5 their quantum efficiencies of photodecomposition reduced by a factor of 5 .

6 Conversely, the quantum efficiency of photodecomposition of urea mixed with

7 nontronite at the same molar concentration is potentially twice as high as in the

8 absence of nontronite. These results suggest a strong photoprotective effect of

9 nontronite on the evolution of glycine and adenine and conversely a possible

10 acceleration of the dissociation of urea.

11 The fact that we did not observe such photoprotection for urea in the 12 presence of nontronite could be due to peculiar interactions between the urea 13 molecules and the mineral. As mentioned in section 3.2, the IR spectra of urea in 14 presence of nontronite show evidence for an interaction between urea and $\mathrm{Fe}^{3+}$.

15 One explanation could be that because of its structure, the molecule of urea is 16 more inclined to chelate $\mathrm{Fe}^{3+}$ ions than would glycine and adenine, and as a 17 consequence it undergoes more efficient photo-oxidation and decomposition. A 18 further experiment performed with urea and a nontronite free of $\mathrm{Fe}^{3+}$ in the 19 interlayer space could be done to confirm this hypothesis.

20 For glycine and adenine, a $\mathrm{Fe}^{3+}$ enriched nontronite seems to efficiently 21 preserve these molecules when under martian surface UV irradiation conditions. 
1 Is this photoprotection due to a purely mechanical shielding effect (provided by

2 the mineral grains) or to stabilizing interactions as well between the molecules

3 and the nontronite? We found that, when the amount of nontronite in the sample

4 of glycine was increased by a factor of two (concentration of $1.3 \times 10^{-2}$ mole of

5 molecules per gram of nontronite), the gain of photoprotection was multiplied by

6 a factor of five (see Table 1). If the nontronite only provided a pure mechanical

7 shielding by its grains, this gain would have been at best a factor of two. Thus,

8 this observation indicates that the photoprotection provided by the nontronite is

9 not a purely mechanical shielding effect, but could also be due to stabilizing

10 interactions of the molecules with the mineral surface.

11 Moreover, it is remarkable to note that the quantum efficiencies of

12 photodecomposition are not linearly correlated to the UV absorbance of the

13 samples with and without nontronite. Samples of organic molecules mixed with

14 nontronite have a transmittance in the $200-250 \mathrm{~nm}$ range that is about twice lower

15 than that of samples of pure organic molecules (UV spectra not shown). If

16 nontronite had only a purely mechanical shielding effect on the evolution of the

17 organic molecules, the quantum efficiencies of photodecomposition in presence of

18 nontronite would have been at best twice lower, while they actually were five

19 times lower for glycine and adenine (cf. Table 1). This implies again that the

20 nontronite reduces the photodecomposition of these molecules by some other

21 mechanism than mere shielding. Electrostatic interactions of the molecules in the 
1 interlayer of the nontronite and/or on the clay edges are possible explanations.

2 Such interaction of the molecules with nontronite may offer more possibilities to

3 dissipate their excess energy due to the absorption of a photon and/or more

4 possibilities for the fragments of the photodissociated molecules to recombine.

5

6 From the few observations described above, we can deduce the following

7 empirical relation, linking the concentration of the molecule in the nontronite $(C$,

8 in "mol per gram of nontronite") to the efficiency of its photodecomposition

9 ( $\Phi_{\text {molecule in nontronite }}$, in “photodecomposed molecule per photon in the 200-250

10 nm range”):

$11 \Phi_{\text {molecule in nontronite }} \approx \Phi_{\text {pure molecule }} \times 5^{-\frac{2.6 \times 10^{-2}}{C}}$

(Equation 1)

12 Reasoning in term of orders of magnitude, we can also write the following

13 relation, where $x$ is the order of magnitude of the mass ratio of organic molecules

14 (glycine or adenine) in the nontronite:

$$
\Phi_{\text {molecule in nontronite }} \approx \Phi_{\text {pure molecule }} \times 5^{-\frac{1}{x}}
$$

(Equation 2)

16 In our experiments, $x$ is equal to 1 . But for natural terrestrial samples of

17 phyllosilicates, $x$ is comprised between $10^{-3}$ and $10^{-2}$ (Bonaccorsi, 2011). The

18 relation above indicates that, for such low concentrations of molecules in

19 nontronite, the efficiency of photodecomposition would be virtually 0 (lower than

$2010^{-73}$ molecule photon $^{-1}$ ), and thus the clay would provide a complete 
1 photoprotection against UV radiation at the surface of Mars. However, more data

2 points would be needed to confirm the range of $x$ values for which Equation 2 is

3 valid.

4

-----Figure 10 should be here-----

7 4.2. Photoproducts and evolution of molecular structures

$9 \quad$ The goal of these experiments performed in the presence of nontronite was

10 also to search for new compounds produced from physico-chemical processes

11 initiated by the clay mineral. But taken as a whole, the results we obtained

12 included no unambiguous detection of a new compound that formed specifically

13 due to the presence of nontronite.

$14 \quad$ IR analysis of the solid phases of glycine samples with nontronite revealed

15 the same products than those observed after UV irradiation of pure glycine

16 samples: tentative peptide bond formation and water formation.

17 For adenine, the IR spectra show the appearance of absorption bands

18 similar to those obtained after UV irradiation of pure adenine samples (see Fig.

19 8b). The adenine photoproduct(s) indicated here suggests a kind of

20 heteropolymeric structure, possibly of high molecular weight (Poch et al., 2014).

21 Regarding urea, the simulation experiment performed in the presence of 
1 nontronite showed detection of the production of cyanate ion $\mathrm{OCN}^{-}$with IR

2 spectroscopy, as was the case for pure urea samples submitted to UV radiation

3 (see Fig. 6b). However, no trace of ammonium ions $\mathrm{NH}_{4}{ }^{+}$was detected, and a new

4 vibration mode associated to the cyanate ion was observed, which may have been

5 due to interaction of cyanate with $\mathrm{Fe}^{3+}$ ions and/or nontronite layers.

7 4.3. Implications for the search of organic molecules on Mars

$9 \quad$ The surface of Mars has been exposed to the current flux of ultraviolet 10 radiation for at least 3 billion years. Of course, it was not the intent of this study to

11 reproduce the equivalent of several billion years of chemical evolution in the

12 laboratory. However, our experiments were designed to indicate the relative

13 resistance of several molecules when exposed to UV radiation at the surface of

14 Mars, and show the influence of nontronite clay mineral (does it provide

15 protection or catalysis?). Such data are essential input for guiding and interpreting

16 in situ analyses performed when searching for organics in martian soil. The

17 irradiation experiments performed on pure organics (Poch et al., 2014) resulted in

18 molecular half-lives of 10 to 100 hours at the surface of Mars, indicating that UV

19 irradiation is the principal driver of chemical evolution of organics in the active

20 (i.e., aeolian-mobile) layer and in the fresh subsurface materials exposed by

21 impacts. Aeolian weathering and dust deposition that exposes and hides soil 
1 particles from direct UV light are likely to control the timescale and the extent of

2 this UV-driven evolution of organics. The photodissociation quantum yields in the

3 presence of nontronite (presented in Table 1), and their empirical extrapolation

4 provided by Equation 2, could be used in a numerical model that takes into

5 account such exposing and hiding effects as well as input rates of organics from

6 micro-meteoritic sources at the surface (Moores et al., 2007; Moores and

7 Schuerger, 2012). The balance between the input rates and the photodissociation

8 rates can then give an estimate on the amount of organics that could be expected

9 in martian soil. Qualitatively, our work also shows that the absorption of radiation

10 by solid organic layers can lead to the formation of new molecules in the solid

11 phase that are more resistant to subsequent irradiation (see the case of adenine in

12 section 3.3.4.2. and mellitic acid by Poch et al. 2014). Some solid organic layers

13 exposed to UV radiation could thus exhibit long-term stability.

14 To conclude, these experiments performed in the presence of $\mathrm{Fe}^{3+}$ -

15 nontronite revealed a pronounced photoprotective effect of this iron-enriched clay

16 mineral on the evolution of glycine and adenine due to both physical shielding

17 and protective physico-chemical interactions (see Fig. 10 and Table 1).

18 Conversely, we did not observe any catalytic or stoechiometric degradation

19 caused by surface groups of the mineral matrix (such as $\mathrm{Fe}^{3+}$, $\mathrm{OH}$ or $\mathrm{H}_{2} \mathrm{O}$ ); if they

20 occur at all, it would be on a longer timescale than the photodecomposition due to

21 UV photons. 
$1 \quad$ However, our experiments also showed that some molecules embedded in 2 nontronite might undergo more effective dissociation, as observed for urea. This 3 may indicate a selective protection of some specific organic molecules by

4 nontronite under Mars surface conditions. Furthermore, is this reactivity observed

5 for urea in the presence of nontronite due to photocatalytic processes, and

6 therefore limited to the surfacic UV-penetrating layer of nontronite? Or is it due to

7 oxidation processes that could possibly occur deeper in the subsurface? Other

8 simulation experiments, as those proposed in section 5, could provide

9 complementary information relative to these questions.

\section{5. Conclusion}

14 This work focused on the study of the effect of nontronite, an abundant 15 clay mineral in many locations at Mars, and on the evolution of organic molecules 16 in simulated martian surface conditions. Our results reveal a pronounced 17 photoprotective effect of nontronite on the evolution of glycine and adenine. No 18 new product of evolution was firmly identified, but qualitative and quantitative 19 results obtained with urea suggest a particular reactivity in the presence of

20 nontronite, leading to a possible increase of its dissociation rate. Thus, nontronite

21 efficiently preserves at least some organic molecules under Mars surface UV 
1 irradiation and is consequently a good target to consider in the search for these

2 molecules at the surface of Mars.

3 In this study, the prepared samples contained a comparable mass of

4 organic molecules and nontronite, or even an excess of organics (see Table 1).

5 They could be representative of a deposit obtained after the evaporation of a warm

6 small pond of liquid water, that has concentrated organic molecules and contains

7 phyllosilicates at the surface of Mars. These samples could also be representative

8 of meteorites or micrometeorites that contain solid organic layers in close

9 interaction with clay minerals (Pearson et al., 2002). To prepare samples

10 representative of a fluvio-lacustrine environment on ancient Mars, a lower mass

11 ratio of organic molecules compared to the phyllosilicate must be obtained. To do

12 so, future experiments would have to perform several washing steps to remove the

13 molecules that do not interact with the surface, and reduce the molecule/mineral

14 ratio, as discussed by Lambert (2008). Additionally, because our samples consist

15 of a mixture of nontronite grains and organics, we cannot precisely evaluate the

16 clay layer thickness needed to provide the photoprotection of the organics. To

17 overcome this limitation, samples could be prepared by vapor deposition of the

18 organic molecules onto a mineral layer of known thickness prepared beforehand.

19 However, such a sample preparation method, via adsorption from the gas phase, is

20 unrealistic in the context of early Mars. Moreover, the chemical interaction of the

21 molecules with the mineral surface would most probably be different from the 
1 case of adsorption from aqueous solutions: no adsorption in the interlayer space

2 and absence of water co-adsorbed with the molecule. To sum up, there is probably

3 no ideal preparation method for environmental analogs of clay containing

4 organics. But the comparison of the results obtained by several experiments

5 performed with these different kinds of samples could help to better understand

6 the complex influence of the mineral on the evolution of the organic molecules.

7 Finally, beyond nontronite, future experiments could expand this work to

8 other minerals that may have concentrated organic molecules, like other types of

9 clay minerals (montmorillonite, saponite etc.) and sulfates, halite, carbonates, or

10 silica (Farmer and Des Marais, 1999). How do these minerals, which are known

11 on Earth to concentrate and preserve organics, affect the evolution of organic

12 molecules under Mars-like environmental conditions? In the future, it would also

13 be interesting to study the effect of oxidants such as hydrogen peroxide $\left(\mathrm{H}_{2} \mathrm{O}_{2}\right)$

14 (Encrenaz et al., 2012), perchlorates $\left(\mathrm{ClO}_{4}^{-}\right)$(Hecht et al., 2009), and their

15 derivatives such as hypochlorite ( $\mathrm{ClO}^{-}$) (Quinn et al., 2013) with regard to the

16 molecular evolution at the surface and subsurface of Mars. Furthermore, in the

17 frame of future missions designed to search for potential biosignatures on

18 astrobiologically relevant ancient environments on Mars (Mustard et al., 2013),

19 investigation into the chemical evolution of molecules of biological origin (fatty

20 acids, porphyrins etc.) or biomarkers (hopanoids, steroids etc.) embedded in their

21 mineral matrix would be of prime interest. 


\section{Acknowledgements}

3 The authors wish to thank the French National Program of Planetology

4 (PNP), the Pierre Simon Laplace Institute (IPSL), and the Institut Universitaire de

5 France (IUF). This manuscript benefited from useful comments and suggestions

6 of two anonymous reviewers.

8 Author Disclosure Statement

$9 \quad$ No competing financial interests exist.

12 Tables

13

\begin{tabular}{|c|c|c|c|c|}
\hline Sample & $\begin{array}{c}\text { mole per } \\
\text { gram of } \\
\text { nontronite }\end{array}$ & $\begin{array}{l}\text { molecule / } \\
\text { nontronite } \\
\text { mass ratio }\end{array}$ & $\begin{array}{l}\text { Quantum efficiency of } \\
\text { photodecomposition 200-250 } \mathrm{nm} \\
\text { (molecule photon }^{-1} \text { ) }\end{array}$ & $\begin{array}{l}\text { Product(s) of evolution } \\
\text { (FTIR anylsis) }\end{array}$ \\
\hline Glycine & \multicolumn{2}{|c|}{ pure glycine } & $6.3 \pm 5.2 \times 10^{-3}$ & $\mathrm{H}_{2} \mathrm{O}$, amide? \\
\hline Glycine + nontronite & $2.6 \times 10^{-2}$ & 2.0 & $1.2 \pm 1.1 \times 10^{-3}$ & $\mathrm{H}_{2} \mathrm{O}$, amide? \\
\hline Glycine + 2Xnontronite & $1.3 \times 10^{-2}$ & 1.0 & $2.4 \pm 2.1 \times 10^{-4}$ & $\mathrm{H}_{2} \mathrm{O}$, amide? \\
\hline Urea & \multicolumn{2}{|c|}{ pure urea } & $1.3 \pm 6.0 \times 10^{-3}$ & $\mathrm{OCN}^{-} \mathrm{NH}_{4}^{+}$ \\
\hline Urea + nontronite & $2.6 \times 10^{-2}$ & 1.6 & $2.9 \pm 2.3 \times 10^{-3}$ & $\mathrm{OCN}^{-}, \mathrm{O}=\mathrm{C}=\mathrm{N}-\mathrm{H} ?$ \\
\hline Adenine & \multicolumn{2}{|c|}{ pure adenine } & $1.0 \pm 0.9 \times 10^{-4}$ & $\begin{array}{c}-\mathrm{NH}_{2}, \mathrm{R}-\mathrm{C} \equiv \mathrm{N} / \mathrm{R}-\mathrm{N} \equiv \mathrm{C}, \\
-\mathrm{C}=\mathrm{C}-\mathrm{C}=\mathrm{N}-\end{array}$ \\
\hline Adenine + nontronite & $2.6 \times 10^{-2}$ & 3.6 & $2.0 \pm 1.4 \times 10^{-5}$ & $\begin{array}{c}-\mathrm{NH}_{2}, \mathrm{R}-\mathrm{C} \equiv \mathrm{N} / \mathrm{R}-\mathrm{N} \equiv \mathrm{C}, \\
-\mathrm{C}=\mathrm{C}-\mathrm{C}=\mathrm{N}-\end{array}$ \\
\hline
\end{tabular}


1 Table 1: Summary of the chemical evolution of glycine, urea, and adenine

2 exposed to Mars-like UV irradiation as pure solid organic deposits or in the 3 presence of nontronite at $218 \pm 2 \mathrm{~K}$ and $6 \pm 1$ mbar. Samples annotated “+ 4 nontronite" contain the same mass of nontronite and the same number of each

5 molecule. The sample annotated "+ 2Xnontronite" contains twice the amount of 6 nontronite.

\section{$9 \quad$ Figure Legends}

11 FIG.1. Absolute irradiance spectrum received at the top of the sample in the

12 MOMIE simulation device (solid lines) compared to two theoretical irradiance

13 spectra at the surface of Mars (dotted lines) for two extreme scenarios: (1) during

14 northern summer $\left(\mathrm{Ls}=70^{\circ}\right)$ for low dust loading $(\tau=0.1)$, at the equator and local

15 noon (taken from Patel et al. 2002); (2) during spring (vernal equinox) for a dusty

16 day $(\tau=2.0)$, at $60^{\circ} \mathrm{N}$ and local noon (taken from Cockell et al. 2000).

17 Concerning the measured spectra, both the maximum irradiance (labeled

18 "MOMIE max", obtained just after the change of the bulb and the cleaning of the

19 optics) and the minimum irradiance (labeled "MOMIE min", measured on an

20 aged bulb and optical system) are shown (see Poch et al. 2014, sections 2.2 and

212.3 for a detailed discussion). 
2 FIG.2. Transmission electron microscopy (TEM) image of the synthesized

3 nontronite, showing the layered structure of the clay mineral. The width of the

4 interlayer space is comprised between 1.3 and $1.7 \mathrm{~nm}$. Similar TEM images of

5 samples of nontronite mixed with glycine, urea, and adenine do not show a

6 significant variation of the interlayer spacing.

8 FIG.3. (a) View of the surface of a sample of nontronite mixed with glycine, 9 under a binocular microscope. The nontronite grains enriched in Fe (III) appear 10 yellowish-brown. (b) Three-dimensional view of the surface of a sample of 11 nontronite mixed with glycine obtained by interference microscopy. The thin 12 layer deposited on the $\mathrm{MgF}_{2}$ window contains grains (aggregates of clay and 13 organics) of all sizes up to $25 \mu \mathrm{m}$, the largest ones on average between 10 and 15 $14 \mu \mathrm{m}$. The image area is $1.217 \times 0.926 \mathrm{~mm}$. The area on the right has been 15 excavated to allow measurement of the altitude 0 (surface of the $\mathrm{MgF}_{2}$ window).

17 FIG.4. (a) In situ IR transmission spectra showing the evolution of glycine in the 18 presence of nontronite during UV irradiation at Martian mean temperature (218 \pm $192 \mathrm{~K}$ ) and pressure (6 \pm 1 mbar) in the MOMIE simulation chamber. Red arrows 20 indicate new absorption bands increasing with irradiation time at around $3240 \mathrm{~cm}^{-}$

$21{ }^{1}\left(\mathrm{H}_{2} \mathrm{O}\right)$ and $1720-1680 \mathrm{~cm}^{-1}$ (amide?). The flux of photons from 200 to $250 \mathrm{~nm}$ 
1 was evaluated to be $1.2 \pm 0.8 \times 10^{20}$ photon $\mathrm{m}^{-2} \mathrm{~s}^{-1}$ for this experiment. (b)

2 Comparison of the infrared spectra obtained after UV irradiation of pure glycine

3 (data from Poch et al. 2013) and glycine mixed with nontronite. Both curves were

4 obtained by subtracting the spectrum of the non-irradiated sample from the

5 spectrum recorded after UV irradiation. For spectral assignments see

$6 \quad$ Supplementary Table $1 . *$ instrumental artifact.

8 FIG.5. Normalized absorbance of the IR absorption bands of glycine during its

9 evolution in the MOMIE simulation chamber in the presence of nontronite. The

10 evolution of three samples is presented on this graph: red and dark-red data point

11 samples $(\boldsymbol{-}, \downarrow)$ were obtained from a sample of glycine mixed at a concentration of

$122.6 \times 10^{-2}$ mole of molecules per gram of nontronite, while orange data point

13 samples $(\bullet)$ were obtained from a sample of glycine mixed at a concentration of

$141.3 \times 10^{-2}$ mole of molecules per gram of nontronite. See section 3.3.2.2 for details.

15 The equivalent irradiation time on this figure corresponds to a flux of photons 16 from 200 to $250 \mathrm{~nm}$ of $1.2 \pm 0.8 \times 10^{20}$ photon $\mathrm{m}^{-2} \mathrm{~s}^{-1}$.

18 FIG.6. (a) In situ IR transmission spectra showing the evolution of urea in the 19 presence of nontronite during UV irradiation at martian mean temperature (218 \pm

$202 \mathrm{~K}$ ) and pressure (6 $\pm 1 \mathrm{mbar})$ in the MOMIE simulation chamber. The blue

21 arrow indicates a new absorption band increasing with irradiation time at around 
$12250-2220 \mathrm{~cm}^{-1}$, which was not observed after irradiation of pure urea. The flux

2 of photons from 200 to $250 \mathrm{~nm}$ has been evaluated to be $1.7 \pm 1.1 \times 10^{19}$ photon

$3 \mathrm{~m}^{-2} \mathrm{~s}^{-1}$ for this experiment. (b) Comparison of the infrared spectra obtained after

4 UV irradiation of pure urea (data from Poch et al. 2014) and urea mixed with

5 nontronite. Both curves were obtained by subtracting the spectrum of the non-

6 irradiated sample from the spectrum recorded after UV irradiation. For spectral

7 assignments see Supplementary Table 2 and Supplementary Table 3.

8 *instrumental artifact.

10 FIG.7. Normalized absorbance of the IR absorption bands of urea during its

11 evolution in the MOMIE simulation chamber in the presence of nontronite. The

12 equivalent irradiation time on this figure corresponds to a flux of photons from 13200 to $250 \mathrm{~nm}$ of $1.2 \pm 0.8 \times 10^{20}$ photon $\mathrm{m}^{-2} \mathrm{~s}^{-1}$.

15 FIG.8. (a) In situ IR transmission spectra showing the evolution of adenine in the 16 presence of nontronite during UV irradiation at martian mean temperature (218 \pm $172 \mathrm{~K})$ and pressure (6 \pm 1 mbar) in the MOMIE simulation chamber. The evolution 18 of the spectra during the simulation is so weak that it cannot be seen without 19 plotting the differential spectrum below. The flux of photons from 200 to $250 \mathrm{~nm}$

20 was evaluated to be $1.2 \pm 0.8 \times 10^{20}$ photon $\mathrm{m}^{-2} \mathrm{~s}^{-1}$ for this experiment. (b)

21 Comparison of the IR spectra obtained after UV irradiation of pure adenine (data 
1 from Poch et al. 2014) and urea mixed with nontronite. Both curves were obtained

2 by subtracting the spectrum of the non-irradiated sample from the spectrum

3 recorded after UV irradiation. For spectral assignments see Supplementary Table

$4 \quad 4$ * *instrumental artifact.

5

6 FIG.9. Normalized absorbance of the IR absorption bands of adenine during its

7 evolution in the MOMIE simulation chamber in the presence of nontronite $(\bullet)$, or

8 as a pure organic deposit ( $\circ$ ) containing the same amount of adenine. The

9 equivalent irradiation time on this figure corresponds to a flux of photons from

10200 to $250 \mathrm{~nm}$ of $1.2 \pm 0.8 \times 10^{20}$ photon $\mathrm{m}^{-2} \mathrm{~s}^{-1}$.

11

12 FIG.10. Quantum efficiency of photodecomposition from 200 to $250 \mathrm{~nm}$ for

13 glycine, urea, and adenine with or without nontronite, exposed to Mars-like UV

14 radiation (from mean values presented in Table 1). For discussion regarding the

15 error bars, see section 4.1 and Poch et al. (2014) section 3.1.

16

17

18

19

20

21 


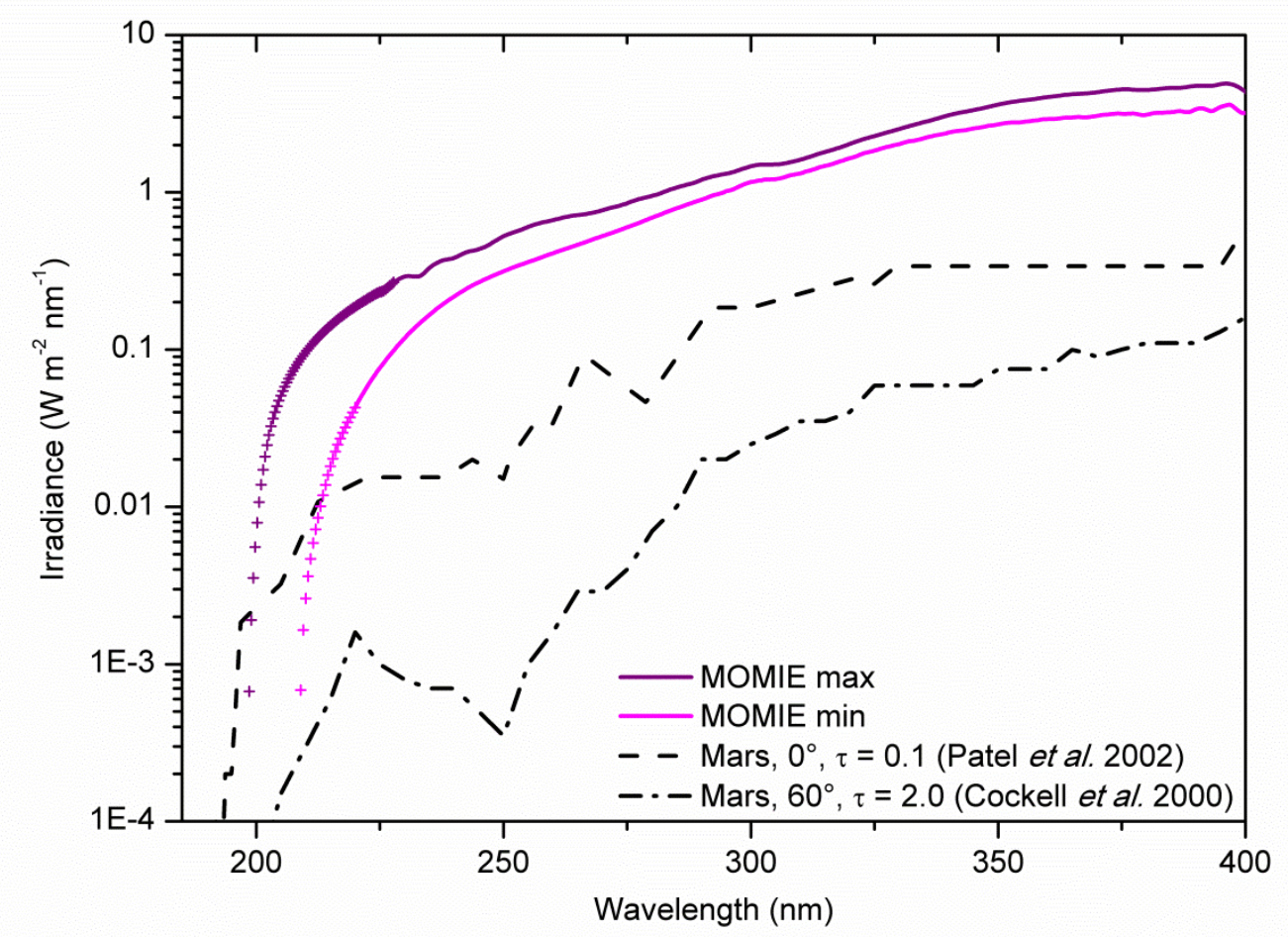

8

$9 \quad$ Fig. 1

10 
2

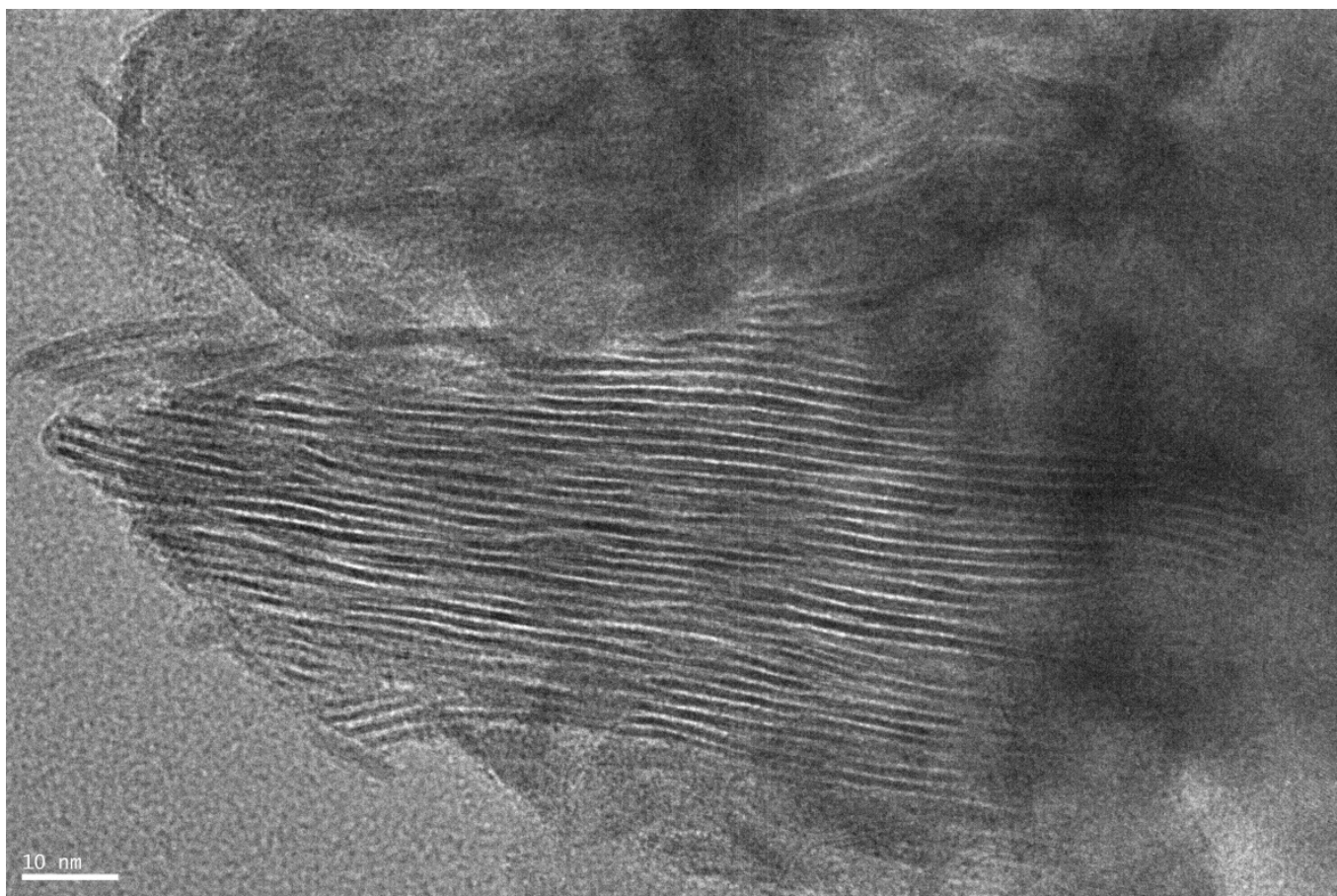

$4 \quad$ Fig. 2

5

6

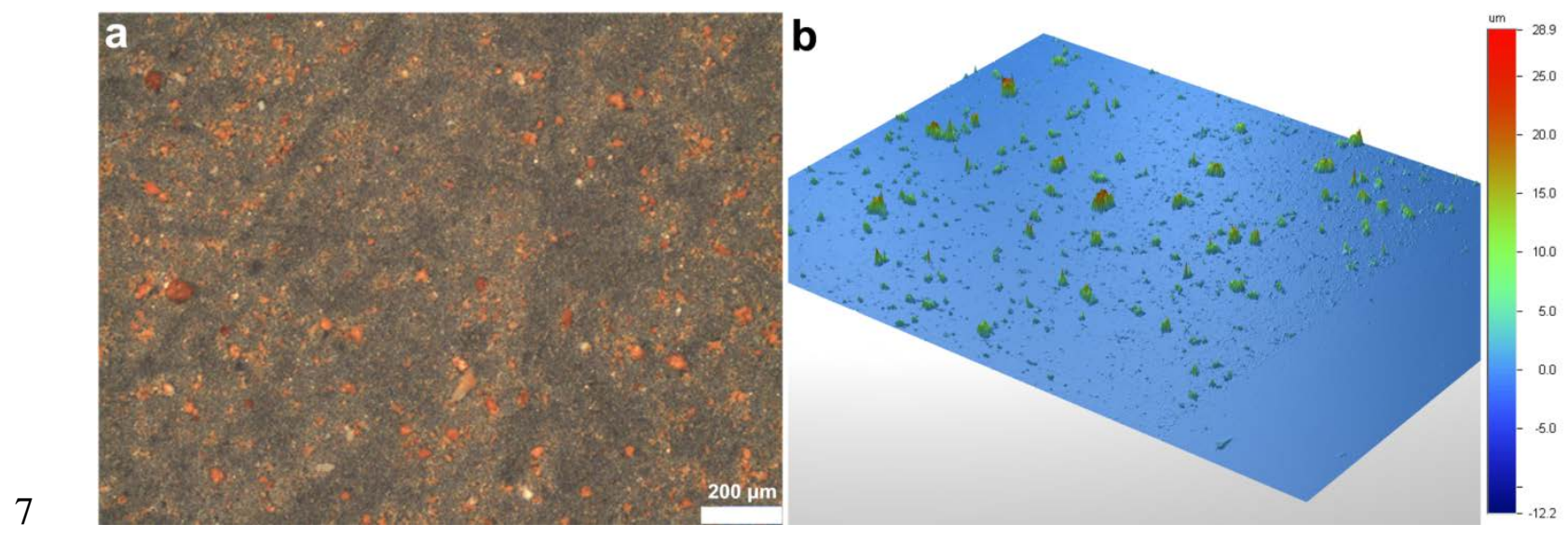


$1 \quad$ Fig. 3

2 
a

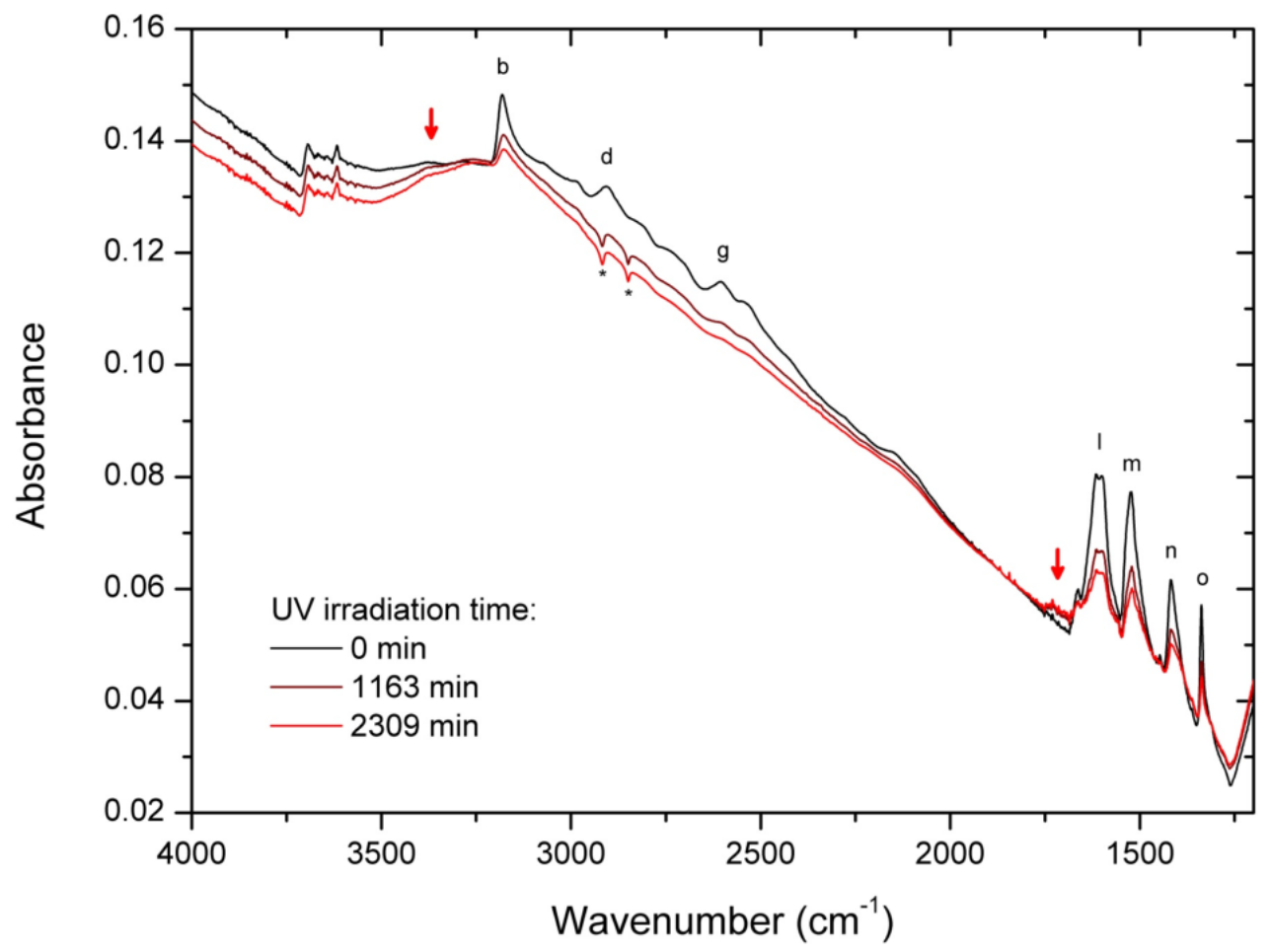

b

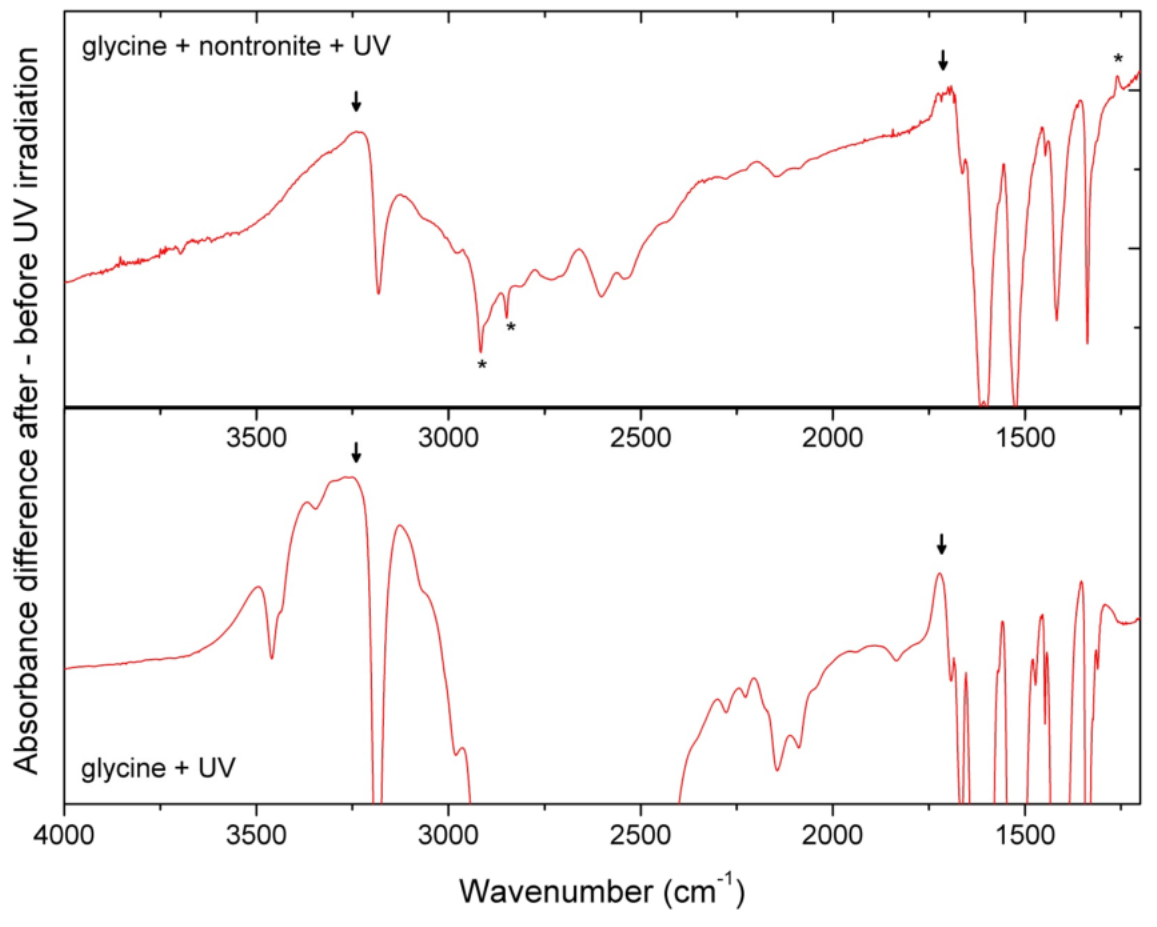


Fig. 4

2

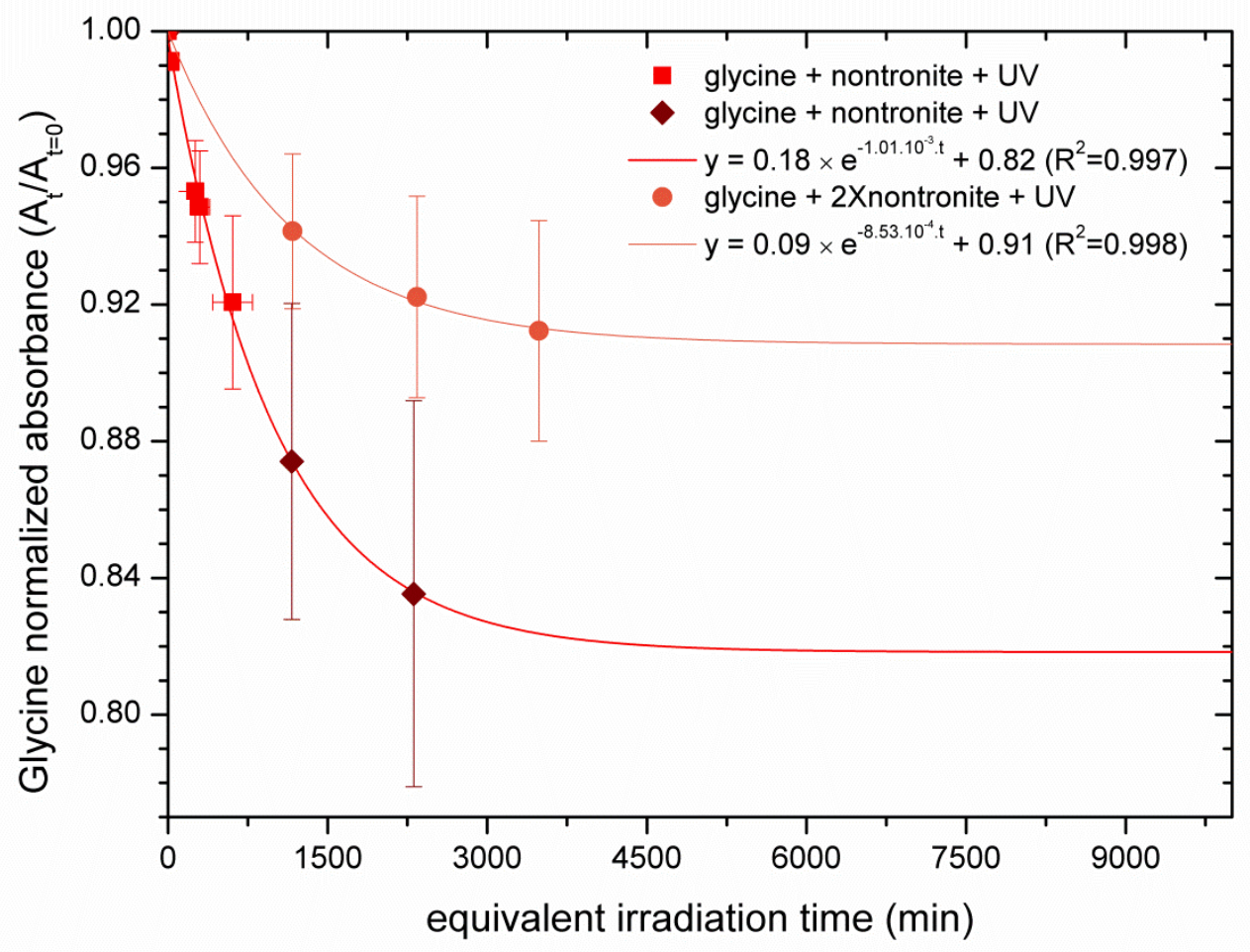

4

$5 \quad$ Fig. 5

6 


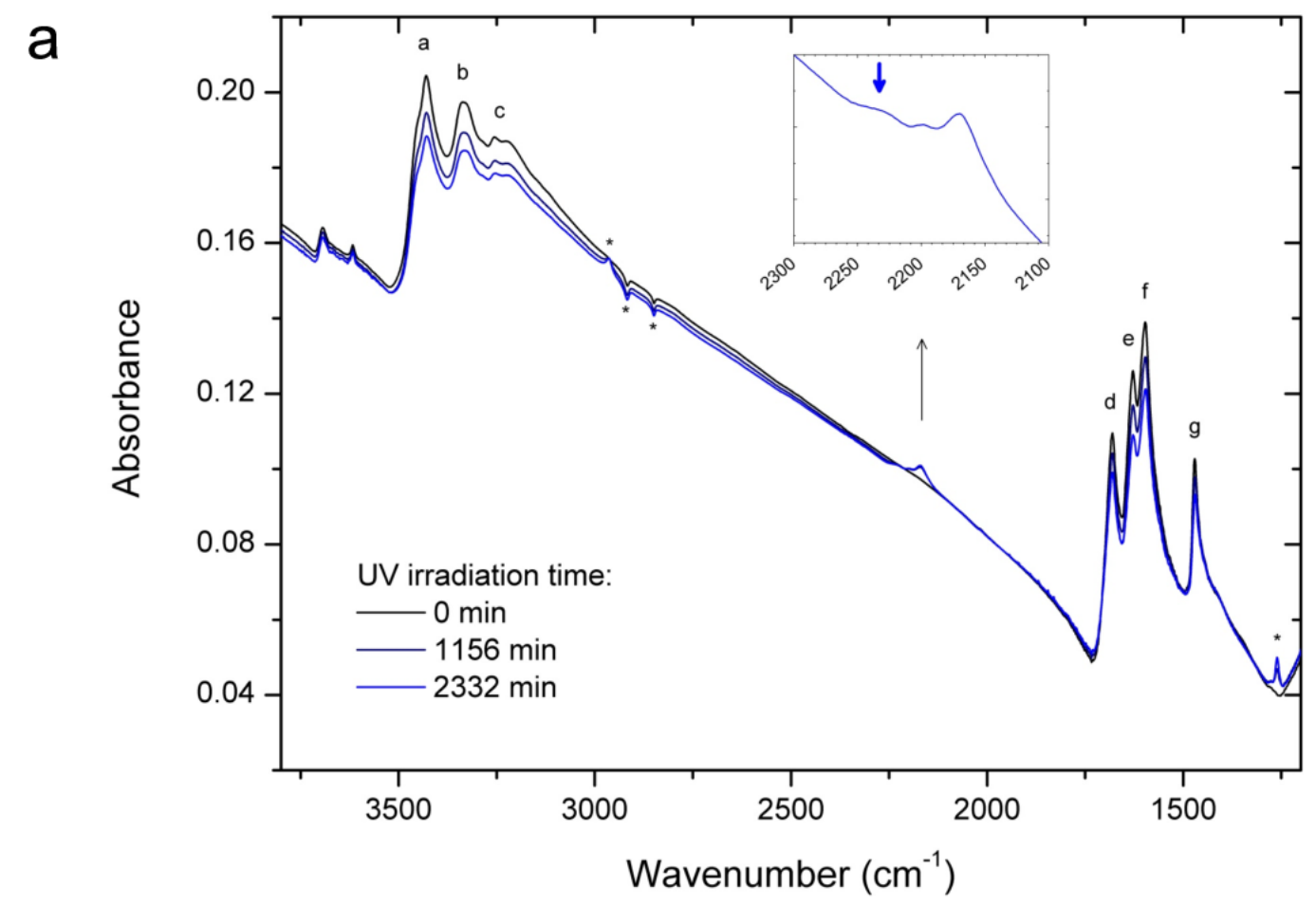

b

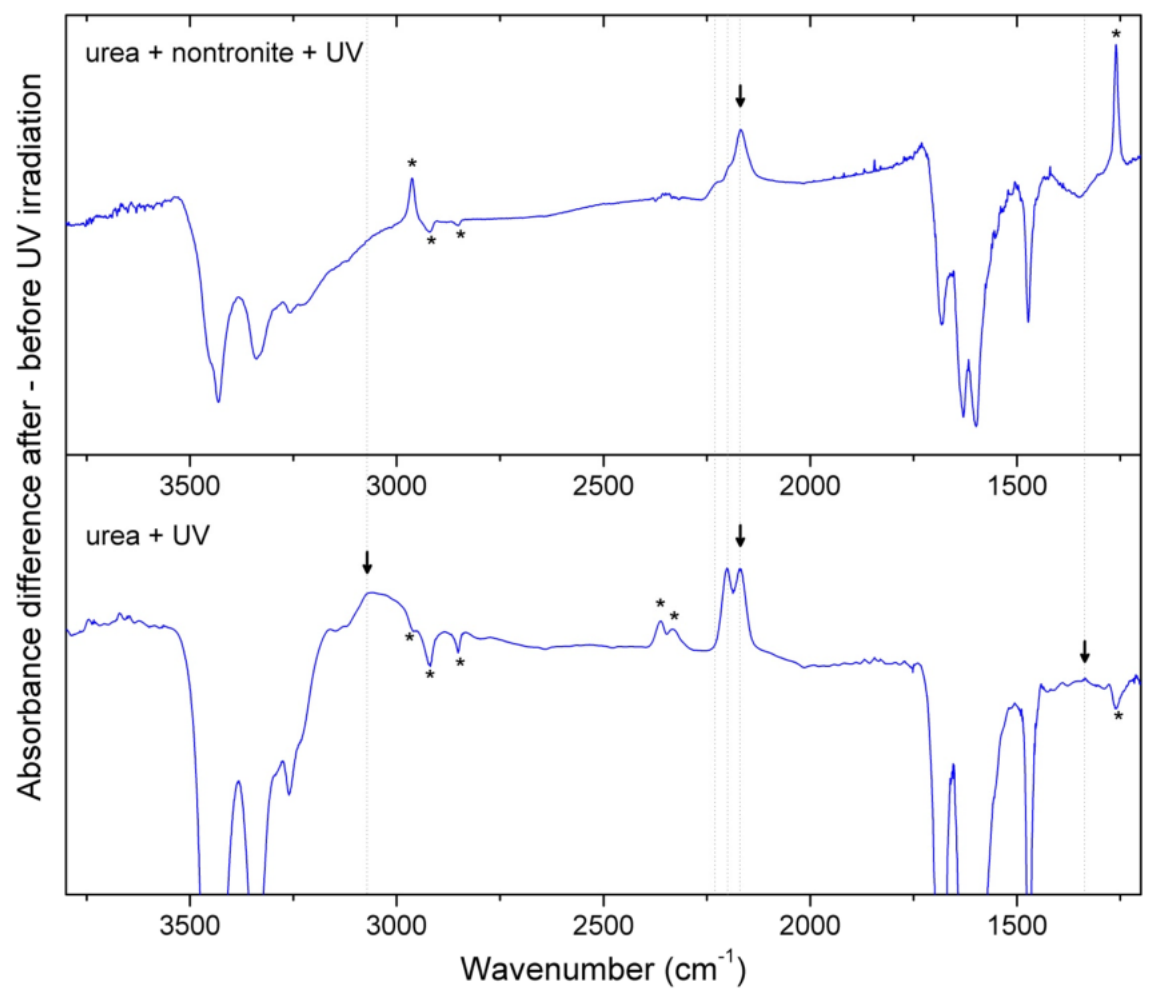


Fig. 6

2

3

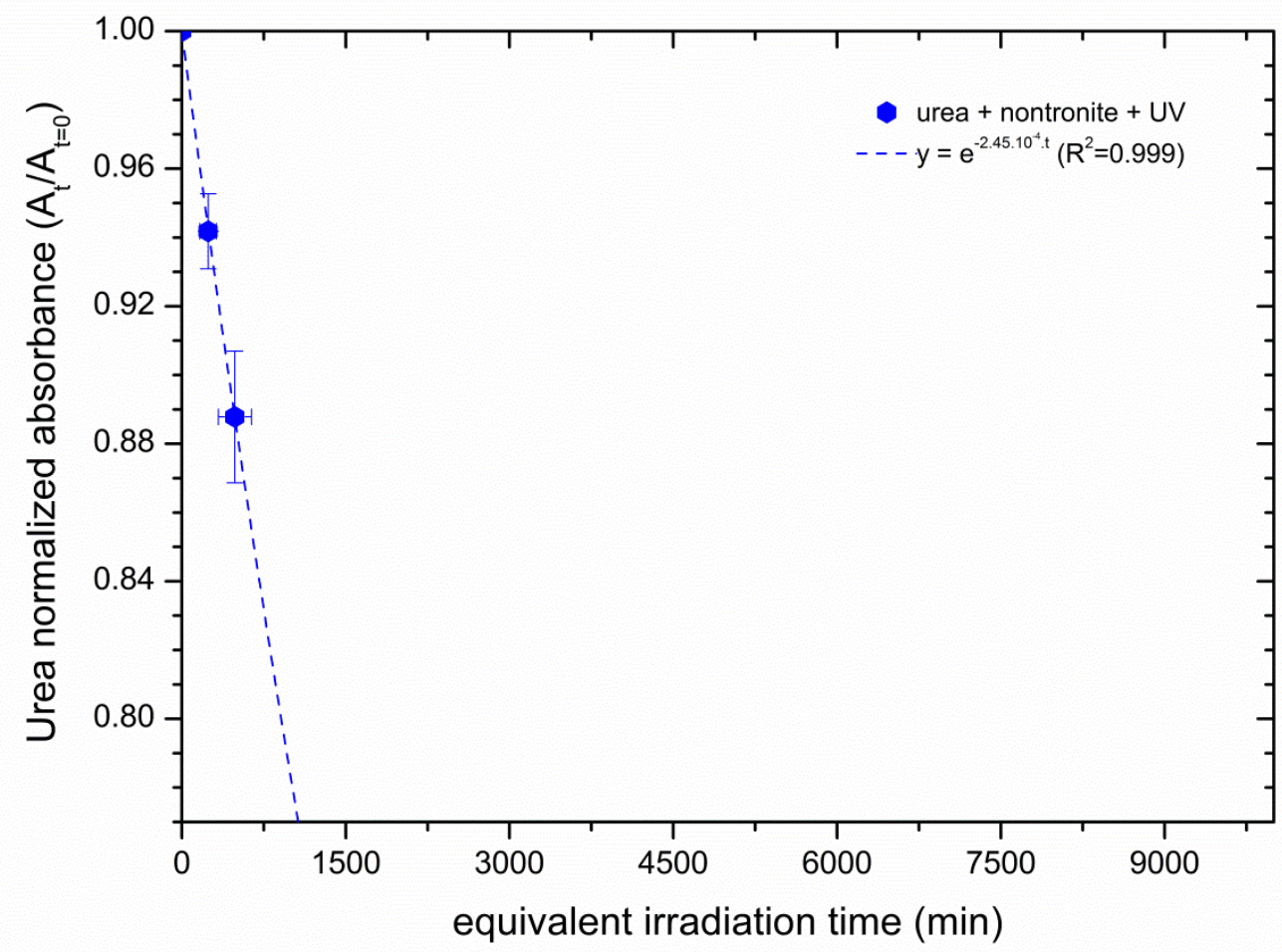

4

$\begin{array}{ll}5 & \text { Fig. } 7\end{array}$

6 


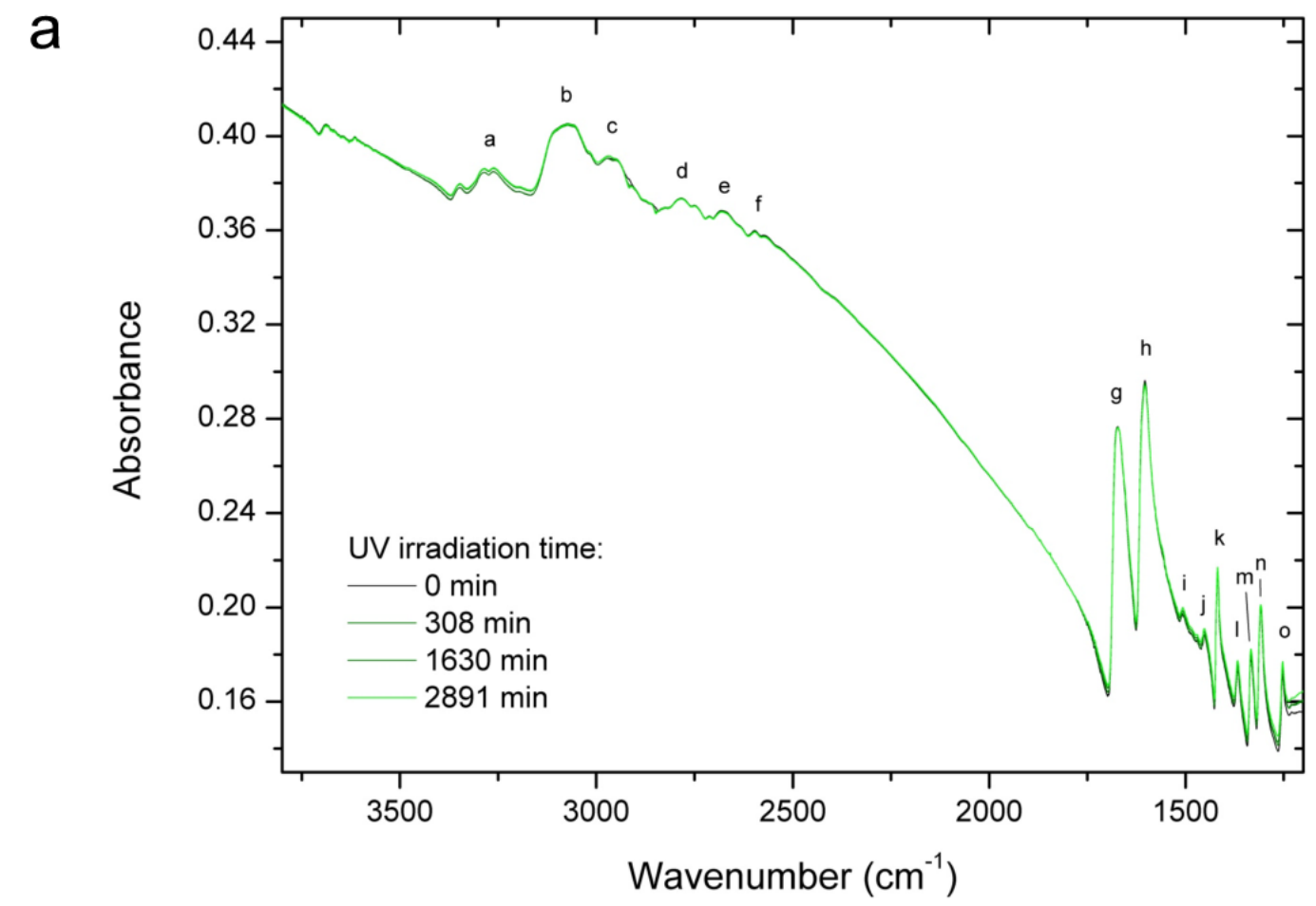

b

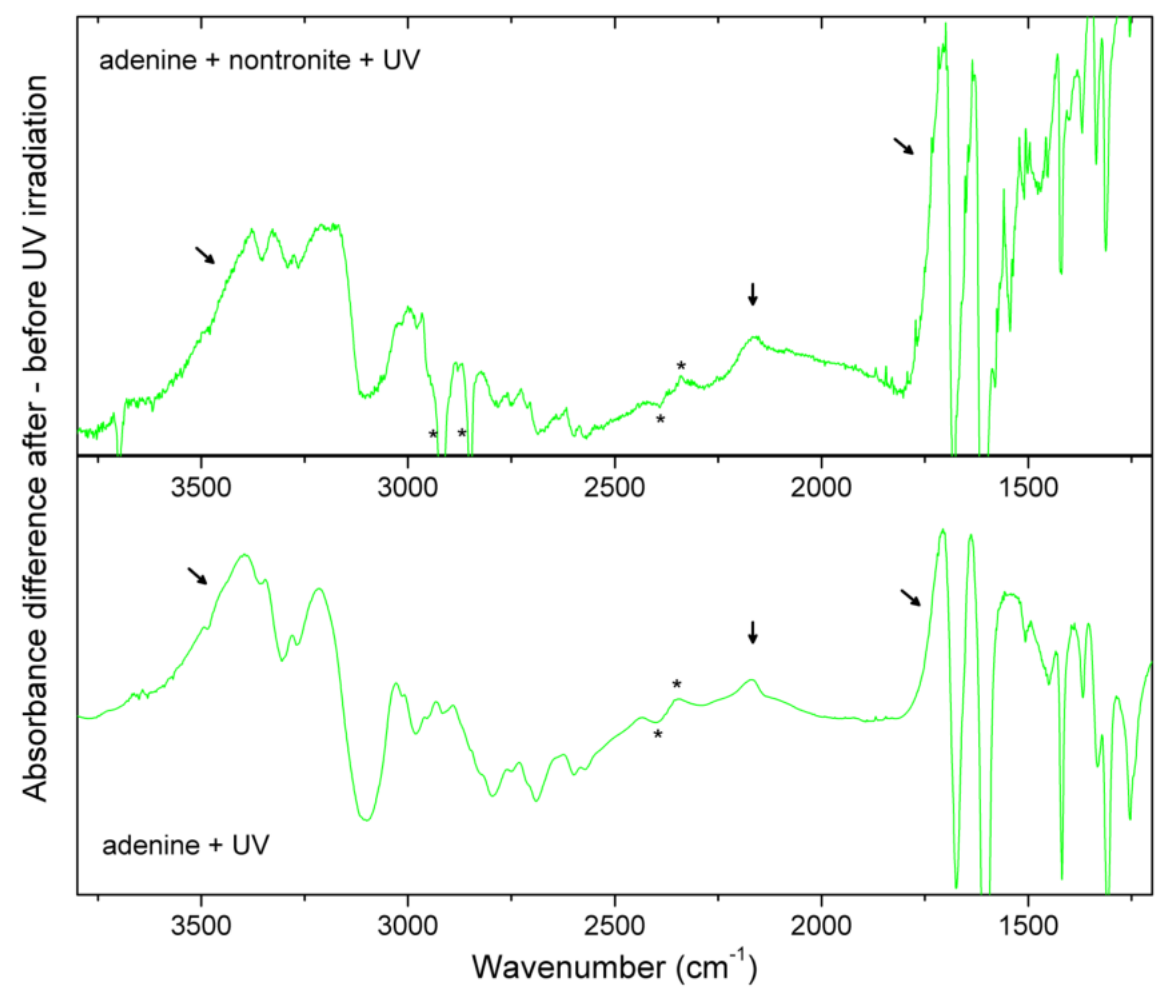


Fig. 8

2

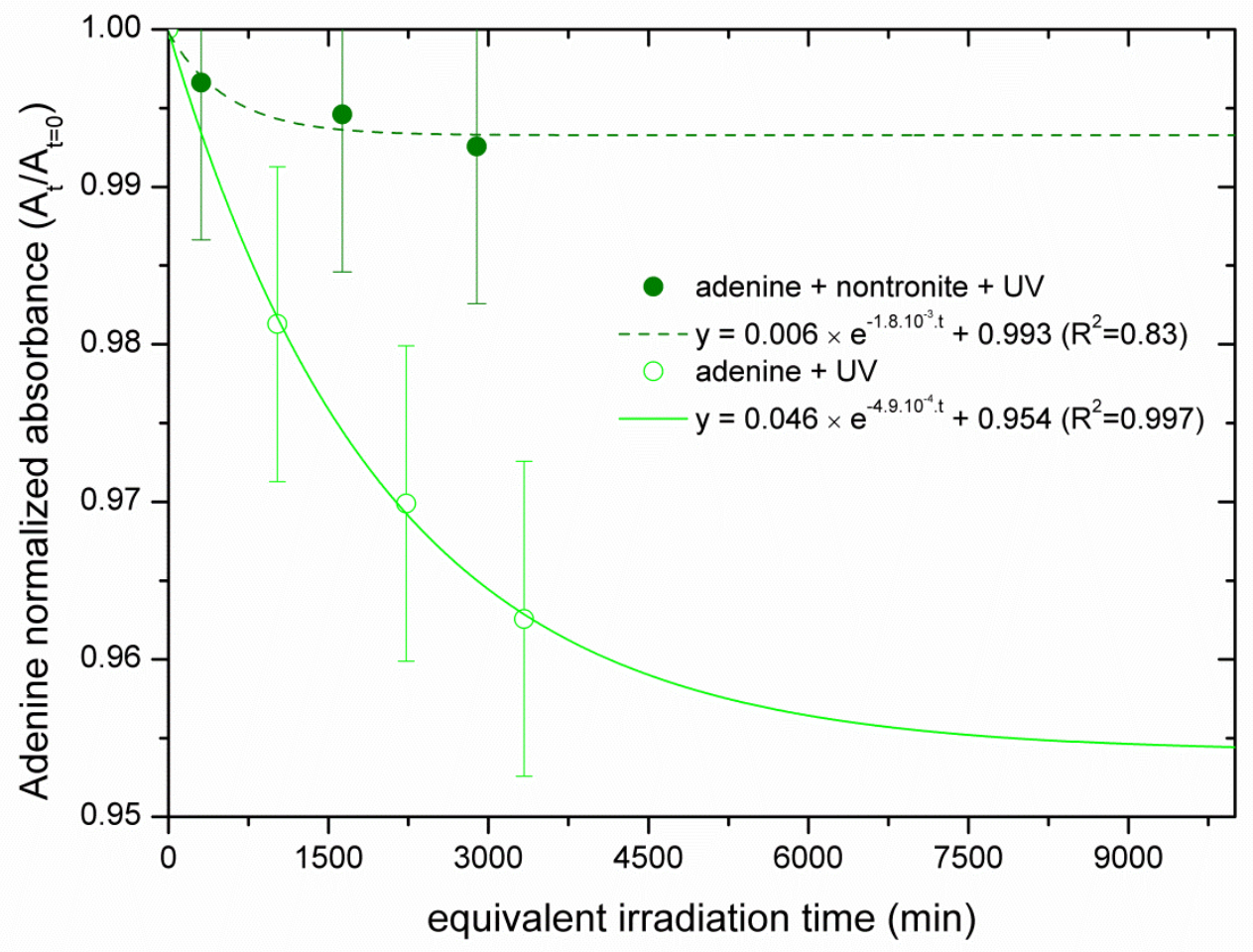

3

$4 \quad$ Fig. 9

5

6

7 


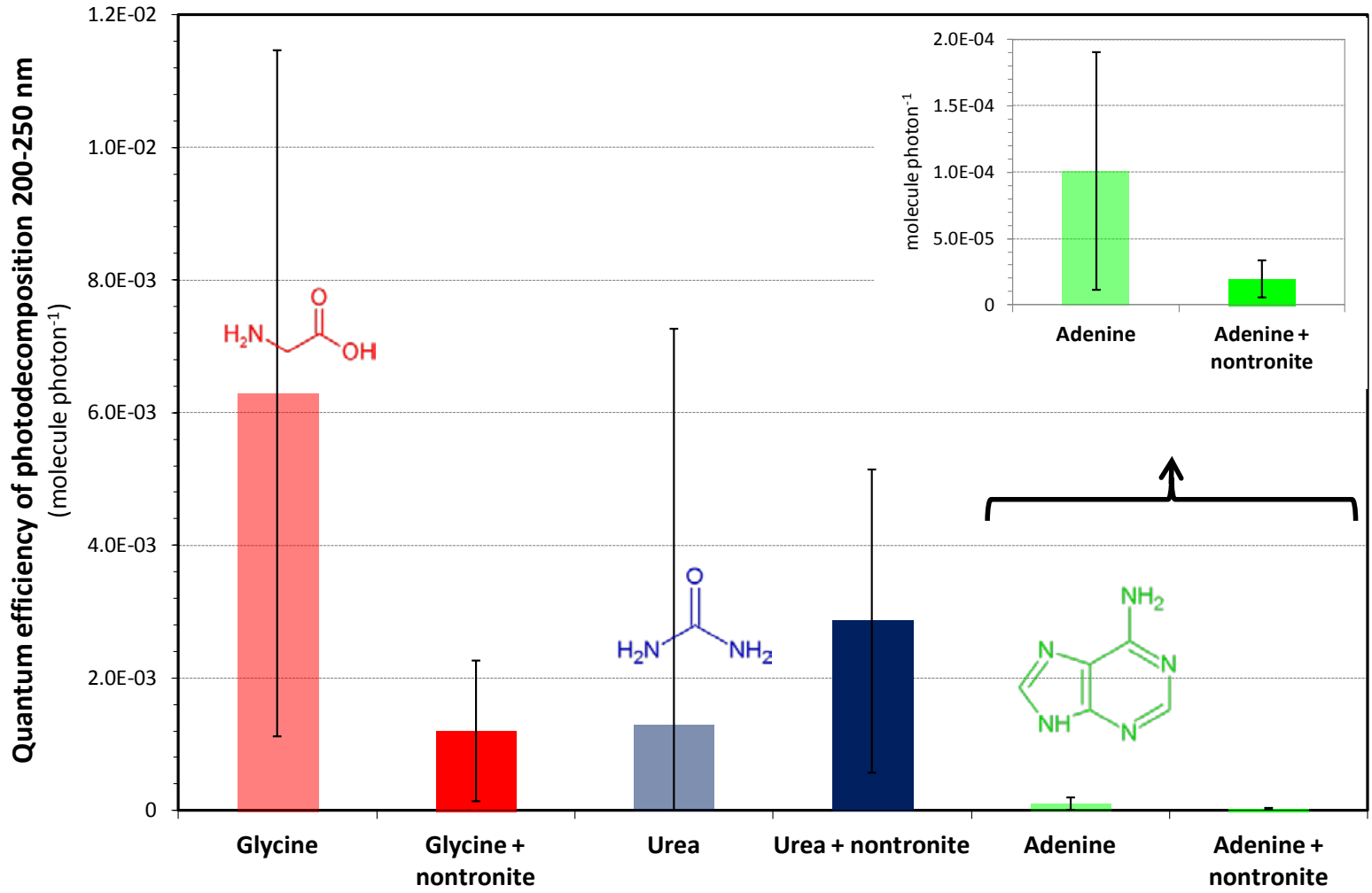

2 Fig. 10

3

4

6

7

8

9

10

11 


\section{References}

3 Albarede, F. (2009) Volatile accretion history of the terrestrial planets and dynamic implications. Nature, 461, 1227-1233.

5 Bibring, J.P., Langevin, Y., Mustard, J.F., Poulet, P., Arvidson, R., Gendrin, A., 6 Gondet, B., Mangold, N., Pinet, P., and Forget F. (2006) Global

9 Bonaccorsi, R. (2011) Preservation Potential and Habitability of Clay Mineralsand Iron-Rich Environments: Novel Analogs for the 2011 Mars Science Laboratory Mission. In: STROMATOLITES: Interaction of Microbes with Sediments. edited by V Tewari and J Seckbachs, Springer Netherlands, p 705-722.

14 Condie, K.C. (2011) Earth as an Evolving Planetary System. Elsevier Science.

15 Dartnell, L.R., Desorgher, L., Ward, J.M., and Coates, A.J. (2007) Modelling the surface and subsurface Martian radiation environment: Implications for astrobiology. Geophysical research letters, 34, L02207, doi:10.1029/2006GL027494.

19 Davis, W.L., and McKay, C.P. (1996) Origins of life: a comparison of theories and application to Mars. Origins of Life and Evolution of the Biosphere, 26, 61-73. 
1 Encrenaz, T., Greathouse, T.K., Lefèvre, F., and Atreya, S.K. (2012) Hydrogen peroxide on Mars: Observations, interpretation and future plans. Planetary and Space Science, 68, 3-17.

4 Farmer, J.D., and Des Marais, D.J. (1999) Exploring for a record of ancient

7 Fassett, C.I., and Head III, J.W. (2008) The timing of martian valley network activity: Constraints from buffered crater counting. Icarus, 195, 61-89.

9 Garry, J.R.C., Ten Kate, I.L., Martins, Z., Nornberg, P., and Ehrenfreund, P. (2006) Analysis and survival of amino acids in Martian regolith analogs. Meteoritics \& Planetary Science, 41, 391-405.

Gerakines, P.A., and Hudson, R.L. (2013) Glycine's Radiolytic Destruction in Ices: First in situ Laboratory Measurements for Mars. Astrobiology, 13, $647-655$.

Hecht, M.H., Kounaves, S.P., Quinn, R.C., West, S.J., Young, S.M.M., Ming, D.W., Catling, D.C., Clark, B.C., Boynton, W.V., Hoffman, J., DeFlores, 18 perchlorate and the soluble chemistry of martian soil at the Phoenix lander site. Science, 325, 64-67. 
1 Hintze, P.E., Buhler, C.R., Schuerger, A.C., Calle, L.M., and Calle, C.I. (2010)

2 Alteration of five organic compounds by glow discharge plasma and UV

3 light under simulated Mars conditions. Icarus, 208, 749-757.

4 Hoehler, T.M., and Westall, F. (2010) Mars exploration program analysis group

5 goal one: determine if life ever arose on Mars. Astrobiology, 10, 859-867.

6 Huestis, D.L., Bougher, S.W., Fox, J.L., Galand, M., Johnson, R.E., Moses, J.I.,

7 Pickering, J.C. (2008) Cross Sections and Reaction Rates for Comparative

8 Planetary Aeronomy. Space Science Reviews 139, 63-105.

9 Jain, R., Awasthi, A.K., Tripathi, S.C., Bhatt, N.J., and Khan, P.A. (2012)

10 Influence of solar flare X-rays on the habitability on the Mars. Icarus, 220, $11 \quad 889-895$

12 Johnson, A.P., and Pratt, L.M. (2010) Metal-catalyzed degradation and 13 racemization of amino acids in iron sulfate brines under simulated martian

14 surface conditions. Icarus, 207, 124-132.

15 Kennedy, M.J., Pevear, D.R., and Hill, R.J. (2002) Mineral surface control of 16 organic carbon in black shale. Science, 295, 657-660.

17 Kminek, G., and Bada, J.L. (2006) The effect of ionizing radiation on the 18 preservation of amino acids on Mars. Earth and Planetary Science Letters, $19 \quad 245,1-5$.

20 Kuhn, W.R., and Atreya, S.K. (1979) Solar radiation incident on the Martian 21 surface. J Mol Evol, 14, 57-64. 
1 Lambert, J.-F. (2008) Adsorption and polymerization of amino acids on mineral surfaces: a review. Origins of Life and Evolution of Biospheres, 38, 211242.

4 Milliken, R.E., Grotzinger, J.P., and Thomson, B.J. (2010) Paleoclimate of Mars as captured by the stratigraphic record in Gale Crater. Geophys. Res. Lett., 37, L04201, doi:10.1029/2009GL041870.

7 Moores, J., Smith, P., Tanner, R., Schuerger, A., Venkateswaran, K. (2007) The shielding effect of small-scale martian surface geometry on ultraviolet flux. Icarus 192, 417-433.

Moores, J.E., Schuerger, A.C. (2012) UV degradation of accreted organics on 117, E08008, doi:10.1029/2012JE004060.

14 Mortland, M. (1966) Urea complexes with montmorillonite: An infrared absorption study. Clay Minerals, 6, 143-156.

16 Mustard, J.F., Adler, M., Allwood, A., Bass, D.S., Beaty, D.W., Bell III, J.F.,

17 Brinckerhoff, W.B., Carr, M., Des Marais, D.J., Drake, B., Edgett, K.S.,

18 Eigenbrode, J., Elkins-Tanton, L.T., Grant, J.A., Milkovich, S.M., Ming,

19 D., Moore, C., Murchie, S., Onstott, T.C., Ruff, S.W., Sephton, M.A.,

20 Steele, A., and Treiman, A. Report of the Mars 2020 Science Definition

21 Team, 154 pp., posted July, 2013, by the Mars Exploration Program 
Analysis Group (MEPAG). Available online at

2 http://mepag.jpl.nasa.gov/reports/MEP/Mars_2020_SDT_Report_Final.pd

3 f .Oro, J., and Holzer, G. (1979) The photolytic degradation and oxidation

4 of organic compounds under simulated Martian conditions. J Mol Evol, $5 \quad 14,153-160$.

6 Palchik, N.A., Grigorieva, T.N., and Moroz, T.N. (2013) Composition, structure, 7 and properties of iron-rich nontronites of different origins. $8 \quad$ Crystallography Reports, 58, 302-307.

9 Parnell, J., Cullen, D., Sims, M.R., Bowden, S., Cockell, C.S., Court, R., 10 Ehrenfreund, P., Gaubert, F., Grant, W., and Parro, V. (2007) Searching 11 for life on Mars: selection of molecular targets for ESA's aurora ExoMars 12 mission. Astrobiology, 7, 578-604.

13 Patel, M.R., Zarnecki, J.C., and Catling, D.C. (2002) Ultraviolet radiation on the 14 surface of Mars and the Beagle 2 UV sensor. Planetary and Space Science $15 \quad 50,915-927$.

16 Pavlov, A., Vasilyev, G., Ostryakov, V., Pavlov, A., and Mahaffy, P. (2012) 17 Degradation of the organic molecules in the shallow subsurface of Mars 18 due to irradiation by cosmic rays. Geophysical research letters, 39, 19 L13202, doi:10.1029/2012GL052166. 
1 Pearson, V.K., Sephton, M.A., Kearsley, A.T., Bland, P.A., Franchi, I.A., and

2 Gilmour, I. (2002) Clay mineral-organic matter relationships in the early

3 solar system. Meteoritics \& Planetary Science, 37, 1829-1833.

4 Poch, O., Kaci, S., Stalport, F., Szopa, C., and Coll, P. (2014) Laboratory insights

5 into the chemical and kinetic evolution of several organic molecules under

6 simulated Mars surface UV radiation conditions. Icarus, 242, 50-63.

7 Poch, O., Noblet, A., Stalport, F., Correia, J.J., Grand, N., Szopa, C., and Coll, P.

8 (2013) Chemical evolution of organic molecules under Mars-like UV

9 radiation conditions simulated in the laboratory with the "Mars organic

10 molecule irradiation and evolution" (MOMIE) setup. Planetary and Space

$11 \quad$ Science, 85, 188-197.

12 Poulet, F., Carter, J., Bishop, J.L., Loizeau, D., and Murchie, S.M. (2014) Mineral

13 abundances at the final four curiosity study sites and implications for their

14 formation. Icarus, 231, 65-76.

15 Quinn, R.C., Martucci, H.F.H., Miller, S.R., Bryson, C.E., Grunthaner, F.J., and

16 Grunthaner, P.J. (2013) Perchlorate Radiolysis on Mars and the Origin of

17 Martian Soil Reactivity. Astrobiology, 13, 515-520.

18 Schuerger, A.C., Fajardo-Cavazos, P., Clausen, C.A., Moores, J.E., Smith, P.H., 19 and Nicholson, W.L. (2008) Slow degradation of ATP in simulated

20 martian environments suggests long residence times for the biosignature

21 molecule on spacecraft surfaces on Mars. Icarus, 194, 86-100. 
1 Shkrob, I.A., and Chemerisov, S.D. (2009) Light induced fragmentation of

2 polyfunctional carboxylated compounds on hydrated metal oxide particles:

3 from simple organic acids to peptides. The Journal of Physical Chemistry

$4 \quad C, 113,17138-17150$.

5 Shkrob, I.A., Chemerisov, S.D., and Marin, T.W. (2010) Photocatalytic

6 Decomposition of Carboxylated Molecules on Light-Exposed Martian

7 Regolith and its Relation to Methane Production on Mars. Astrobiology,

$8 \quad 10,425-436$.

9 Smith, D.S., and Scalo, J. (2007) Solar X-ray flare hazards on the surface of Mars.

$10 \quad$ Planetary and Space Science, 55, 517-527.

11 Smith, D.S., Scalo, J., and Wheeler, J.C. (2004) Transport of ionizing radiation in

12 terrestrial-like exoplanet atmospheres. Icarus, 171, 229-253.

13 Solomon, S.C., Aharonson, O., Aurnou, J.M., Banerdt, W.B., Carr, M.H., 14 Dombard, A.J., Frey, H.V., Golombek, M.P., Hauck, S.A., Head, J.W., 15 Jakosky, B.M., Johnson, C.L., McGovern, P.J., Neumann, G.A., Phillips, 16 R.J., Smith, D.E., and Zuber, M.T.(2005) New Perspectives on Ancient $17 \quad$ Mars. Science, 307, 1214-1220.

18 Stalport, F., Coll, P., Szopa, C., and Raulin, F. (2008) Search for organic 19 molecules at the Mars surface: The "Martian Organic Material Irradiation 20 and Evolution" (MOMIE) project. Advances in Space Research, 42, 2014212018. 
1 Stalport, F., Coll, P., Szopa, C., and Raulin, F. (2009) Investigating the 2 photostability of carboxylic acids exposed to Mars surface radiation 3 conditions. Astrobiology, 9, 543-549.

4 Stalport, F., Guan, Y.Y., Coll, P., Szopa, C., Macari, F., Raulin, F., Chaput, D., 5 and Cottin, H. (2010) UVolution, a Photochemistry Experiment in Low 6 Earth Orbit: Investigation of the Photostability of Carboxylic Acids 7 Exposed to Mars Surface UV Radiation Conditions. Astrobiology, 10, 449-461.

9 Stoker, C.R., and Bullock, M.A. (1997) Organic degradation under simulated Martian conditions. Journal of Geophysical Research, 102, 10881-10888.

11 Tanaka, K.L., Robbins, S.J., Fortezzo, C.M., Skinner, J.A., and Hare, T.M. (2013)

12 The digital global geologic map of Mars: Chronostratigraphic ages, 13 topographic and crater morphologic characteristics, and updated 14 resurfacing history. Planetary and Space Science, 95, 11-24.

15 Ten Kate, I.L., Garry, J.R.C., Peeters, Z., Foing, B., and Ehrenfreund, P. (2006) 16 The effects of Martian near surface conditions on the photochemistry of 17 amino acids. Planetary and Space Science, 54, 296-302.

18 Ten Kate, I.L., Garry, J.R.C., Peeters, Z., Quinn, R., Foing, B., and Ehrenfreund, 19 P. (2005) Amino acid photostability on the Martian surface. Meteoritics \& Planetary Science, 40, 1185-1193. 
1 Thomson, B.J., Bridges, N.T., Milliken, R., Baldridge, A., Hook, S.J., Crowley, 2 J.K., Marion, G.M., de Souza Filho, C.R., Brown, A.J., and Weitz, C.M. 3 (2011) Constraints on the origin and evolution of the layered mound in 4 Gale Crater, Mars using Mars Reconnaissance Orbiter data. Icarus, 214, $5 \quad 413-432$.

6 Vago, J., Gardini, B., Kminek, G., Baglioni, P., Gianfiglio, G., Santovincenzo, A., 7 Bayon, S., and van Winnendael, M. (2006) ExoMars-searching for life on 8 the Red Planet. ESA bulletin, 126, 16-23.

9 Valley, J.W., Peck, W.H., King, E.M., and Wilde, S.A. (2002) A cool early Earth. 10 Geology, 30, 351-354.

11 Westall, F., Loizeau, D., Foucher, F., Bost, N., Betrand, M., Vago, J., and 12 Kminek, G. (2013) Habitability on Mars from a microbial point of view. 13 Astrobiology, 13, 887-897.

14 Zent, A.P., and McKay, C.P. (1994) The chemical reactivity of the Martian soil 15 and implications for future missions. Icarus, 108, 146-157. 